\title{
Modelling sediment transport from bare rilled hillslopes by areally averaged transport equations
}

\author{
Gokmen Tayfur \\ Department of Civil Engineering, Izmir Institute of Technology, Gulbahce Kampus, Urla, Izmir, 35340, Turkey
}

Received 9 February 2006; received in revised form 22 May 2006; accepted 19 July 2006

\begin{abstract}
Treating the dynamics of sediment transport as two-dimensional on interrill-areas and as one-dimensional in rill sections, areally averaged sheet sediment transport equations are developed. The two-dimensional sheet sediment transport equation is averaged over an individual interrill-area width and then along the interrill-area length to obtain local-scale areally averaged interrill-area sheet sediment transport equation (local-scale areal averaging). Similarly, the cross-sectionally-averaged rill sediment transport equation is averaged along an individual rill length to obtain local-scale areally averaged rill sediment transport equation (local-scale areal averaging). In order to minimize computational effort and economize on the number of model parameters, the local-scale areally averaged equations are then averaged over a whole hillslope section (large-scale areal averaging). These equations constitute the areally averaged model. The expectations of the terms containing more than one variable are obtained by the method of regular perturbation. In the large-scale areal averaging it is assumed that all the randomness in the state variable is due to the randomness in the parameters of the process. Comparison of the results obtained from the areally averaged model with those of the point-scale model indicates that the areally averaged model uses far less data and yet it performs as well as the point-scale model. The results of the developed model indicate that on a rilled-surface most of the sediment loads comes from rill sections. The developed model is successfully tested against experimental data obtained from a bare rilled hillslope. It predicted measured runoff and sediment rates with mean absolute errors of $11.07 \mathrm{l} / \mathrm{min}$ and $0.382 \mathrm{~kg} / \mathrm{s}$, respectively.
\end{abstract}

(C) 2006 Elsevier B.V. All rights reserved.

Keywords: Sheet sediment transport; Erosion; Hillslope; Rilled-surface; Averaging; Regular perturbation

\section{Introduction}

Land surfaces usually exhibit irregular microtopographies. In hydrologic modelling an irregular topography is often replaced by a smooth surface, because of the complications arising in the numerical procedures and the extra effort involved in obtaining the microtopographic data at a grid scale needed for the numerical model. Tayfur et al. (1993) and Tayfur and Singh (2004) investigated surface flow and sheet sediment transport (SST) over irregular microtopographic surfaces, respectively, and found that microtopograhy was one of the major factors dominating the temporal and spatial distributions of the state variables, such as flow depth, flow velocity, and sediment concentration.

E-mail address: gokmentayfur@iyte.edu.tr.
Irregular microtopographic surfaces also contain rills, as shown in Fig. 1. The importance of rills to SST has been well established experimentally both in field and laboratory studies (Meyer et al., 1975; Emmett, 1978; Moss and Walker, 1978; Abrahams et al., 1989; and Abrahams and Parsons, 1990; Govindaraju et al., 1992). In hydrologic modelling, however, rills have often been neglected (Govindaraju and Kavvas, 1991; Hairsane and Rose, 1992a; Sander et al., 1996; Lisle et al., 1998; Parlange et al., 1999; Hairsane et al., 1999; and Tayfur, 2001, 2002). Hairsane and Rose (1992b) developed a theoretical model for one-dimensional sediment transport from a rilled-surface. However, the sediment continuity equation and numerical and analytical solutions that they developed for the equation are not valid for the unsteady sediment transport phenomenon. Furthermore, in their study, they made several assumptions: (1) rills are located parallel on a homogenous soil mass; (2) rills have 


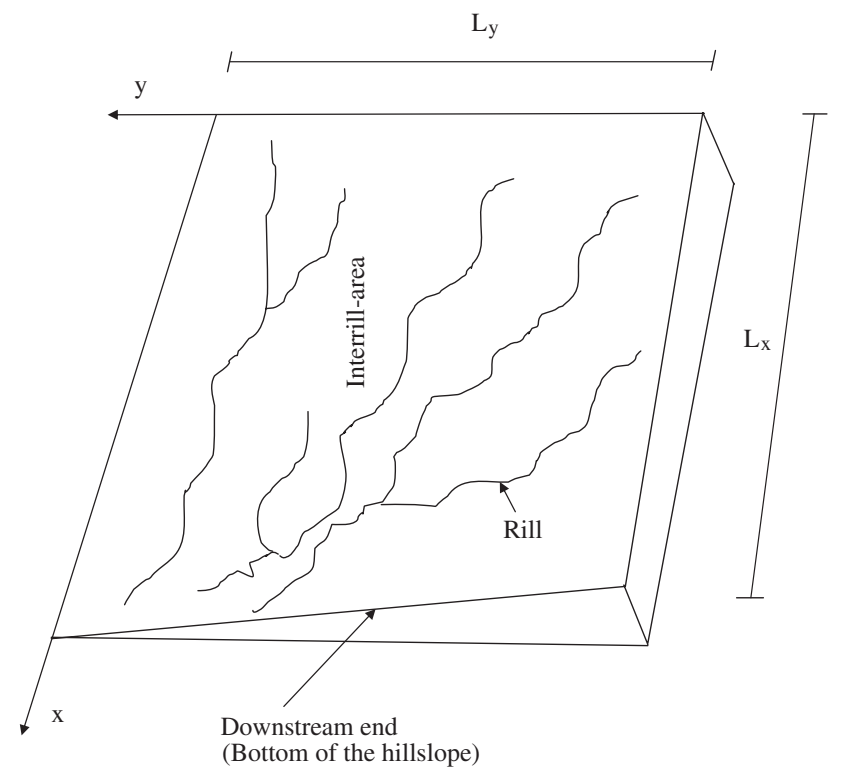

Fig. 1. Schematic representation of a rilled-hillslope.

sediment and water flux contributed to them orthogonally; (3) rills occur at a regular frequency of $N$ rills per unit width measured across the slope; (4) rain falling on an interrill-area is directly captured by an adjacent rill so that downslope delivery of water occurs completely in rills; and (5) volumetric flow rate per rill is equal for all rills. The WEPP hillslope profile erosion model also uses a onedimensional steady-state sediment continuity equation to describe the movement of sediment on a rilled-surface (Bulygin et al., 2002). In the WEPP model, interrill sediment delivery is considered to be space-independent. Interrill-area is conceptualized as a process of sediment delivery to rills, whereby the interrill sediment is either carried off the hillslope by the flow in the rill or deposed in the rill. The models of Hairsane and Rose (1992b) and the WEPP are for equilibrium sediment transport in a rill section and they do not consider movement of flow and sediment on interrillareas. Kavvas and Govindaraju (1992) modelled unsteady state SST over rilled-surfaces. In their model, flow and sediment movement occurs both on interrill-area and in rill sections. However, in their model, there is no interaction between rill and interrill-area sections. Furthermore, their model is in one-dimension and assumes that there is no variability in the microtopography. In reality, however, SST over interrill-areas occurs mostly in two dimensions (2D) due to the variability in the local microtopography and there is lateral sediment load from interrill-areas to adjacent rill sections. Hence, a realistic model of SST needs to consider the movement of flow and sediment on interrill-areas and in rill sections and combine rill sediment transport dynamics with interrill-area SST dynamics.

The objective of this study is therefore to develop areally averaged equations for unsteady and non-uniform SST composed of interacting rill sediment transport and interrillarea SST. The SST would be treated on interrill-areas in 2D with no limitations on the natural variability of the surface microtopography and would account for the interaction occurring between the sediment transport in rills and the SST on interrill-areas. The equations would conserve mass and momentum at the hillslope-scale. It is desirable to conserve mass and momentum at the hillslope-scale because in real world problems the detailed microtopographic information is seldom available at very fine scales for employment of pointscale SST equations. At best the average values of model parameters can be estimated at the scale of a whole hillslope by means of digital elevation maps. The areally averaged equations thus derived would constitute the SST model.

\section{Mathematical development}

Sheet sediment transport (SST) induced by rainfall runoff entails: (1) flow dynamics and (2) sediment transport dynamics. Flow dynamics is composed of: (1) interrill-area sheet flow and (2) rill flow. Sediment transport dynamics is also composed of: (1) interrill-area sediment transport and (2) rill sediment transport. In this study, SST over interrill-areas was conceptualized as two-dimensional (2D) and in rills as one-dimensional (1D). From flow dynamics, one computes the flow state variables that, in turn, are used in the SST dynamics to compute the sediment concentration and discharge.

\subsection{Flow dynamics}

\subsubsection{Interrill-area sheet flow}

The kinematic wave equation for $2 \mathrm{D}$ sheet flow is expressed as (Tayfur and Kavvas, 1998):

$\frac{\partial h_{\mathrm{o}}}{\partial t}+\frac{\partial}{\partial x}\left(K_{x} h_{\mathrm{o}}^{1.5}\right)+\frac{\partial}{\partial y}\left(K_{y} h_{\mathrm{o}}^{1.5}\right)=q_{1}$

where

$K_{x}=\frac{C_{\mathrm{z}} S_{\mathrm{ox}}^{0.5}}{\left[1+\left(\frac{S_{\mathrm{ov}}}{S_{\mathrm{ox}}}\right)^{2}\right]^{0.25}}$

$K_{y}=\frac{C_{\mathrm{z}} S_{\mathrm{oy}}^{0.5}}{\left[1+\left(\frac{S_{\mathrm{ox}}}{S_{\mathrm{oy}}}\right)^{2}\right]^{0.25}}$

where $h_{\mathrm{o}}=$ the sheet flow depth $(L) ; q_{1}=$ the net lateral flow (rainfall minus infiltration) $(L / T) ; S_{\mathrm{o} x}$ and $S_{\mathrm{o} y}=$ the bed slopes in $x$ - and $y$-directions, respectively (Fig. 1); and $C_{\mathrm{z}}=$ Chezy's roughness coefficient $\left(L^{1 / 2} / T\right)$. Eq. (1) is a non-linear $2 \mathrm{D}$ depth-averaged equation which conserves mass and momentum at a point-scale. Consequently, it requires point-scale information of physical model parameters.

Local-scale averaging of sheet flow is presented in Tayfur and Kavvas (1994). They averaged the 2D sheet flow Eq. (1) along an interrill-area width $(l)$ (Fig. 3) and quantified the local-scale lateral flow fluxes from adjacent interrill-areas to 


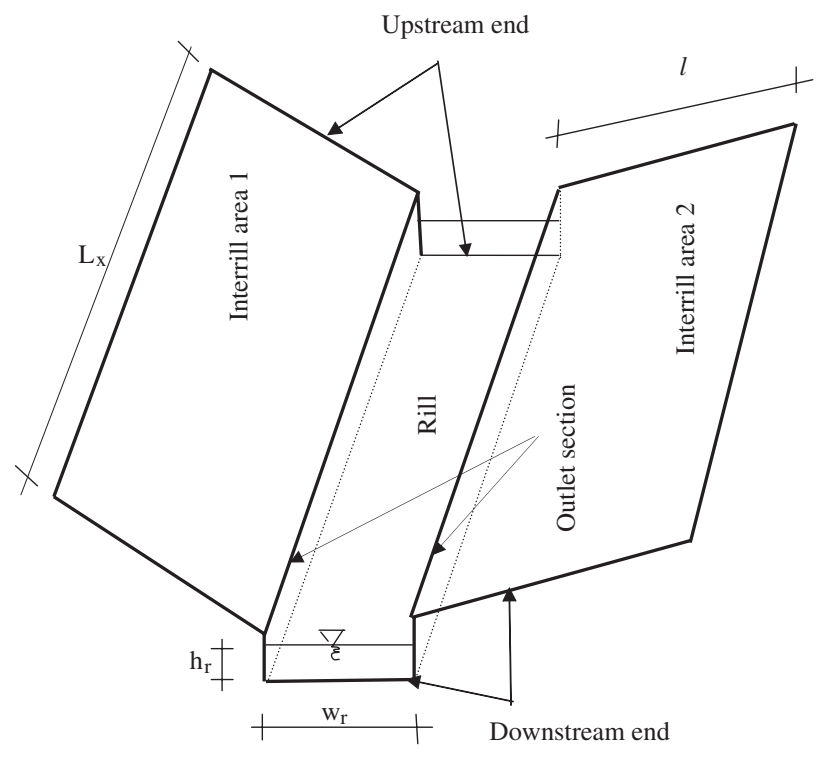

Fig. 2. Detailed representation of a rill section.

the rill section. The resulting local-scale averaged sheet flow equation is (Tayfur and Kavvas, 1994):

$\frac{\partial \bar{h}_{\mathrm{o}}}{\partial t}+\frac{\partial}{\partial x}\left(K_{x}^{\prime} \bar{h}_{\mathrm{o}}{ }^{1.5}\right)=\bar{q}_{1}-1.97 \frac{K_{y}}{l} \bar{h}_{\mathrm{o}}{ }^{1.5}$

where $\bar{h}_{\mathrm{o}}=$ the local-scale averaged interrill-area sheet flow depth $(L) ; \overline{\mathrm{q}}_{1}=$ the local-scale averaged net lateral flow $(L / T)$; $l=$ interrill-area width $(L)$; and $K_{x}^{\prime}=$ the expected value of $K_{x}$ over the local-scale interrill-area width.

In the numerical solution of Eq. (4), one requires the average values of the model parameters over the local-scale interrill-area at each point along the $x$-direction (Fig. 1). Since such a solution is not attractive from the point view of data collection and computation, Tayfur and Kavvas (1998) developed the following local-scale areally averaged interrill-area sheet flow equation:

$\frac{\partial h_{\mathrm{o}}^{\prime}}{\partial t}+\frac{1.97}{L_{x}}\left(K_{x L_{x}}^{\prime} h_{\mathrm{o}}^{\prime 1.5}\right)=q_{1}^{\prime}-3.88 K_{y l}^{\prime} h_{\mathrm{o}}^{\prime 1.5}$

where $h_{\mathrm{o}}^{\prime}=$ the local-scale areally averaged interrill-area sheet flow depth $(L) ; q_{1}^{\prime}=$ the local-scale areally averaged net lateral flow $(L / T) ; K_{y l}^{\prime}=$ expected value of $K_{y l} / l$ over an interrill area; $K_{x_{L x}^{\prime}=}$ the local-scale interrill-area average of $K x$ at the hillslope bottom (Fig. 1). Eq. (5) requires only the average values of the physical model parameters over the whole individual interrill area.

\subsubsection{Rill flow}

The cross-sectionally averaged rill flow equation is expressed as (Tayfur and Kavvas, 1998):

$\frac{\partial h_{\mathrm{r}}}{\partial t}+\frac{\partial}{\partial x}\left[K_{\mathrm{r}} R^{0.5} h_{\mathrm{r}}\right]=q_{1}+1.97 \bar{h}_{\mathrm{o}}^{1.5}\left(\frac{K_{y i}}{w_{\mathrm{r}}}\right)$

where $h_{\mathrm{r}}=$ the cross-sectionally averaged rill flow depth $(L)$; $w_{\mathrm{r}}=$ the rill width $(L) ; K_{\mathrm{r}}=C_{\mathrm{z}} \sqrt{S_{\mathrm{r}}}$, where $S_{\mathrm{r}}=$ the rill bed slope; $R=$ the hydraulic radius $(L)$; and $K_{y i}$ is defined by Eq. (3) $[i=1,2$; two local interrill areas-local interrill-area 1 and local interrill-area 2, Fig. 2].

The second term on the right hand side of Eq. (6) represents the local-scale lateral flow fluxes coming into the rill from the adjacent interrill-areas $[i=1,2$; two adjacent interrill-areas as shown in Fig. 2]. Eq. (6) conserves mass and momentum at the cross-section of a rill (Fig. 3) and assumes no overflow of rills onto interrill-areas. It also assumes that there is no temporal change in rill width. In the numerical solution of Eq. (6), the cross-sectionally averaged values of model parameters are required at each point along the $x$-direction (Fig. 1). Since such a solution is not attractive from the data collection and computational point view, Tayfur and Kavvas (1998) developed the following local-scale areally averaged rill flow equation:

$\frac{\partial h_{\mathrm{r}}^{\prime}}{\partial t}+\left[\frac{1.97 K_{R} h_{\mathrm{r}}^{\prime 1.5}}{\left(w_{\mathrm{r}_{L x}}+\pi h_{\mathrm{r}}^{\prime}\right)^{0.5}}\right]=q_{1}^{\prime}+3.88 h_{\mathrm{o}}^{\prime 1.5} K_{Y_{i}}^{\prime}$

where $h_{\mathrm{r}}^{\prime}=$ the local-scale areally averaged rill flow depth $(L)$; $K_{Y i}=K_{y l i} / w_{\mathrm{r}}, i=1,2$ and $K_{Y i}^{\prime}=\left\langle K_{Y i}>\right.$; and $w_{\mathrm{rLx}}=$ the rill width at the downstream end of the rill $(L)$. The last term on the right hand side of Eq. (7) represents the areal lateral sediment load coming into the rill from the adjacent interrill-areas $[i=1,2$; two adjacent interrill-areas as shown in Fig. 2]. Eq. (7) requires only the average values of physical model parameters of the whole rill.

\subsubsection{Areally averaged flow}

Tayfur and Kavvas (1998) statistically averaged the localscale areally averaged flow Eqs. (5) and (7) over the whole hillslope section (see Fig. 3) to obtain the large-scale (hillslope-scale) areally averaged flow equations for both rill and interrill-area sections. By doing a large-scale areal averaging, they avoided solving for the flow in every rill and

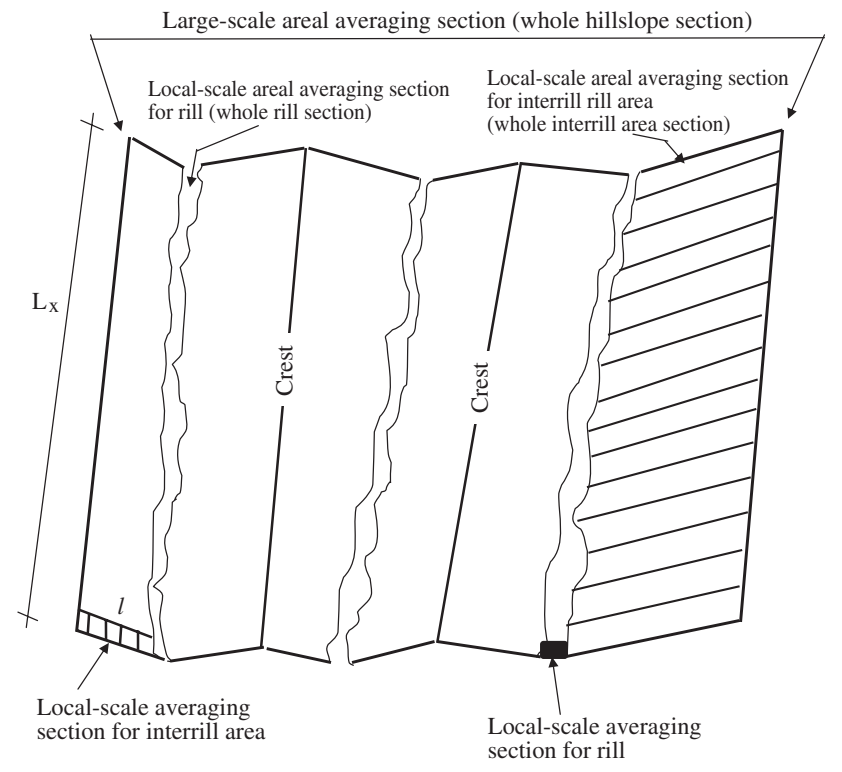

Fig. 3. Details of the averaging sections. 
interrill-area section. Eqs. (8) and (9), respectively, stand for the large-scale (hillslope-scale) areally averaged interrill-area sheet flow and rill flow equations can be expressed as (Tayfur and Kavvas, 1998):

$$
\begin{aligned}
& \frac{\partial h_{\mathrm{o}}^{\prime}\left(\bar{r}^{\prime}\right)}{\partial t}+0.985 \sum_{i=1}^{n} \sum_{j=1}^{n} \operatorname{Cov}\left(r_{i}, r_{j}\right) \\
& \quad \times\left\{\frac{\partial^{2}\left[K_{X}^{\prime}\left(\bar{r}^{\prime}\right) h_{\mathrm{o}}^{\prime 1.5}\left(\bar{r}^{\prime}\right)\right]}{\partial r_{i}^{\prime} \partial r_{j}^{\prime}}+1.97 \frac{\partial^{2}\left[K_{y l}^{\prime}\left(\bar{r}^{\prime}\right) h_{\mathrm{o}}^{\prime 1.5}\left(\bar{r}^{\prime}\right)\right]}{\partial r_{i}^{\prime} \partial r_{j}^{\prime}}\right\} \\
& +1.97\left\{K_{X}^{\prime}\left(\bar{r}^{\prime}\right) h_{\mathrm{o}}^{\prime 1.5}\left(\bar{r}^{\prime}\right)+1.97 K_{y l}^{\prime}\left(\bar{r}^{\prime}\right) h_{\mathrm{o}}^{\prime 1.5}\left(\bar{r}^{\prime}\right)\right\}=\left\langle q_{1}^{\prime}\right\rangle \\
& \quad \frac{\partial h_{\mathrm{r}}^{\prime}\left(\bar{r}^{\prime}\right)}{\partial t}+0.985 \sum_{i=1}^{n} \sum_{j=1}^{n} \operatorname{Cov}\left(r_{i}, r_{j}\right) \\
& \quad \times\left\{\frac{\partial^{2}\left[\frac{K_{R}\left(\bar{r}^{\prime}\right) h_{\mathrm{r}}^{\prime} 1.5\left(\bar{r}^{\prime}\right)}{\left.\left.\left(w_{r_{L x}}+\pi h_{\mathrm{r}}^{\prime} \bar{r}^{\prime}\right)\right)^{0.5}\right]}\right.}{\partial r_{i}^{\prime} \partial r_{j}^{\prime}}-1.97 \frac{\partial^{2}\left[K_{Y_{i}}^{\prime}\left(\bar{r}^{\prime}\right) h_{\mathrm{o}}^{\prime 1.5}\left(\bar{r}^{\prime}\right)\right]}{\partial r_{i}^{\prime} \partial r_{j}^{\prime}}\right\} \\
& +1.97\left\{\frac{K_{R}\left(\bar{r}^{\prime}\right) h_{\mathrm{r}}^{\prime \prime .5}\left(\bar{r}^{\prime}\right)}{\left[w_{r_{L x}}+\pi h_{\mathrm{r}}^{\prime}\left(\bar{r}^{\prime}\right)\right]^{0.5}}-1.97 h_{\mathrm{o}}^{\prime 1.5}\left(\bar{r}^{\prime}\right)\left[K_{Y_{i}}^{\prime}\left(\bar{r}^{\prime}\right)\right]\right\}=\left\langle q_{1}^{\prime}\right\rangle
\end{aligned}
$$

where $h_{\mathrm{o}}^{\prime}\left(\bar{r}^{\prime}\right)$ and $h_{\mathrm{r}}^{\prime}\left(\bar{r}^{\prime}\right)$ are the large-scale areally averaged interrill-area sheet flow depth and rill flow depth at the scale of a hillslope, respectively; the vector random variable $\bar{r}=$ $\left(C_{\mathrm{z}}, S_{\mathrm{o} x}, S_{\mathrm{oy}}, S_{\mathrm{r}}, w_{\mathrm{r}}, l, L_{x}\right)$, and $\bar{r}^{\prime}$ is its hillslope-scale mean vector. Note that Eq. (9) assumes a rectangular rill crosssection (Fig. 2).

To obtain the complete solution to overland flow at the scale of a hillslope, the large-scale areally averaged interrillarea sheet flow Eq. (8) and the large-scale areally averaged rill flow Eq. (9) are solved simultaneously. Eq. (8) is solved first to obtain the areally averaged discharge to the stream at the hillslope bottom from interrill-areas, and the areally averaged discharge going to the rill from interrill-areas located at the left-hand and right-hand sides of the rills. Then Eq. (9) is solved to calculate the areally averaged discharge from a rill to the stream at the bottom of the hillslope. In order to find the total discharge from a hillslope to a neighbouring stream, the number of rills over a hillslope is estimated first. The probability of rill occurrence $\lambda$ is then estimated for the whole hillslope [see Govindaraju and Kavvas (1992) and Kavvas and Govindaraju (1992) for a more complete discussion]. By the weighted averaging, the large-scale areally averaged rill flow discharge to the stream is multiplied by $\lambda$, and the large-scale areally averaged interrill-area sheet flow discharge to the stream is multiplied by $(1-\lambda)$ in order to weigh the relative contributions of rill flows and interrill-area sheet flows to overland flow to the neighbouring stream at the scale of a hillslope. These products are then summed up to determine the total discharge from a hillslope to the neighbouring stream adjacent to the particular hillslope.

\subsection{Sediment transport dynamics}

\subsubsection{Interrill-area sheet sediment transport}

Sheet sediment transport (SST) in 2D on an interrill-area is expressed as (Tayfur, 2001):

$$
\frac{\partial\left(h_{\mathrm{o}} c_{\mathrm{o}}\right)}{\partial t}+\frac{\partial}{\partial x}\left(K_{x} h_{\mathrm{o}}^{1.5} c_{\mathrm{o}}\right)+\frac{\partial}{\partial y}\left(K_{y} h_{\mathrm{o}}^{1.5} c_{\mathrm{o}}\right)=\frac{1}{\rho_{\mathrm{s}}}\left(D_{\mathrm{do}}+D_{\mathrm{fo}}\right)
$$

where

$D_{\mathrm{do}}=\alpha r^{\beta}\left(1-\frac{h_{\mathrm{o}}+l_{\mathrm{d}}}{6.69 r^{0.182}}\right)$

$\left.D_{\mathrm{fo}}=\varphi l \eta\left(\tau_{\mathrm{o}}-\tau_{\mathrm{c}}\right)^{k}=\rho_{\mathrm{s}} c_{\mathrm{o}} q_{\mathrm{o}}\right\rfloor$

where $c_{\mathrm{o}}=$ the sediment concentration by volume on an interrill-area $\left(L^{3} / L^{3}\right)\{\wedge\{0.5\}\} ; \rho_{\mathrm{s}}=$ the sediment particle density $\left(M / L^{3}\right) ; D_{\mathrm{do}}=$ the soil detachment rate by raindrops over an interrill-area $\left(M / L^{2} / T\right) ; D_{\mathrm{fo}}=$ the soil detachment/ deposition rate by sheet flow over an interrill-area $\left(M / L^{2} / T\right)$; $\alpha=$ the soil detachability coefficient $\left(M / L^{2} / L\right) ; \beta=$ an exponent; $r=$ the rainfall intensity $(L / T) ; l_{\mathrm{d}}=$ the loose soil depth $(L) ; \varphi=$ the transfer rate coefficient $(1 / L) ; \eta=$ the soil erodibility coefficient; $\tau_{\mathrm{o}}=$ the interrill-area shear stress $(M /$ $L^{2}$ ), which is stated as $\tau_{\mathrm{o}}=y h_{\mathrm{o}}\left(S_{\mathrm{o} x}^{2}+S_{\mathrm{o} y}^{2}\right)$, where $\gamma=$ the specific weight of water $\left(M / L^{3}\right) ; \tau_{\mathrm{c}}=$ the critical shear stress $\left(M / L^{2}\right)$, which is stated as $\tau_{\mathrm{c}}=\delta\left(\gamma_{\mathrm{s}}-\gamma\right)$, where $\delta=$ a constant, $\gamma_{\mathrm{s}}=$ the specific weight of sediment $\left(M / L^{3}\right)$ and $d=$ the particle diameter $(L) ; k=$ an exponent; and $q_{\mathrm{o}}=$ the unit flow discharge in the flow direction $\left(L^{2} / T\right)$, which is stated as $q_{\mathrm{o}}=\left[\left(K_{x} h_{\mathrm{o}}^{1.5}\right)^{2}+\left(K_{y} h_{\mathrm{o}}^{1.5}\right)^{2}\right]^{0.5}$ (Tayfur, 2001). Eq. (10) is a nonlinear two-dimensional equation that conserves mass and momentum at a point-scale. Consequently, it requires a point-scale information of physical model parameters.

\subsubsection{Local-scale areally averaged interrill-area sheet sediment transport}

The local-scale areally averaged interrill-area SST equation is developed in two stages: 1 . Average the pointscale interrill-area SST Eq. (10) over interrill-area width $(l)$ (Fig. 3) (local-scale averaging). 2. Average the resulting local-scale averaged interrill-area SST equation along the interrill-area length $\left(L_{x}\right)$ (Fig. 3) (local-scale areal averaging).

The point-scale SST Eq. (10) is integrated along the $y$ direction (perpendicular to the resultant $x$-direction) over an individual interrill-area width $(l)$ (Fig. 3$)$ to initiate the localscale averaging:

$$
\begin{aligned}
& \frac{1}{l} \int_{0}^{l} \frac{\partial\left(h_{\mathrm{o}} c_{\mathrm{o}}\right)}{\partial t} d y+\frac{1}{l} \int_{0}^{l} \frac{\partial}{\partial_{x}}\left(K_{x} h_{\mathrm{o}}^{1.5} c_{\mathrm{o}}\right) d y \\
& \quad+\frac{1}{l} \int_{0}^{1} \frac{\partial}{\partial y}\left(K_{y} h_{\mathrm{o}}^{1.5} c_{\mathrm{o}}\right) d y=\frac{1}{l} \int_{0}^{l} \frac{1}{\rho_{\mathrm{s}}}\left(D_{\mathrm{do}}+D_{\mathrm{fo}}\right) d y
\end{aligned}
$$


Integration of Eq. (13) yields:

$$
\begin{aligned}
& \frac{\partial\left\langle h_{\mathrm{o}} c_{\mathrm{o}}\right\rangle}{\partial t}+\frac{\partial}{\partial x}\left\langle K_{x} h_{\mathrm{o}}^{1.5} c_{\mathrm{o}}\right\rangle-\frac{1}{l}\left[K_{x} h_{\mathrm{o}}^{1.5} c_{\mathrm{o}} \frac{d l}{d x}\right]_{y=l} \\
& +\frac{1}{l}\left[K_{x} h_{\mathrm{o}}^{1.5} c_{\mathrm{o}} \frac{d l}{d x}\right]_{y=0}+\frac{1}{l}\left[K_{y} h_{\mathrm{o}}^{1.5} c_{\mathrm{o}}\right]_{y=l}-\frac{1}{l}\left[K_{y} h_{\mathrm{o}}^{1.5} c_{\mathrm{o}}\right]_{y=0} \\
& \quad=\left\langle\frac{1}{\rho_{\mathrm{s}}}\left(D_{\mathrm{do}}+D_{\mathrm{fo}}\right)\right\rangle
\end{aligned}
$$

where \langle\rangle denotes the local-scale averaging operator.

Interrill-areas are like plates as shown in Fig. 3, and rills are like sink lines that collect the material from adjacent interrill-areas. The sediment concentration is assumed to be zero at the crest of an interrill-area. A similar assumption is made by Tayfur and Kavvas (1994) for the flow depth at the crest of an interrill-area. Hence, the sixth term on the left hand side of Eq. (14) becomes zero. interrill-areas are assumed to be basically rectangular with an area width $l=1^{-}+l^{\prime}$. This width is treated as a random variable with a mean $1^{-}$and deviation from the mean as $l^{\prime}$, and assumed to be stochastically independent of the $x$-direction (Tayfur and Kavvas, 1994). The third and fourth terms on the left hand side of Eq. (14) become zero. Hence, Eq. (14) becomes

$$
\begin{aligned}
\frac{\partial\left\langle h_{\mathrm{o}} c_{\mathrm{o}}\right\rangle}{\partial t} & +\frac{\partial}{\partial x}\left\langle K_{x} h_{\mathrm{o}}^{1.5} c_{\mathrm{o}}\right\rangle=\left\langle\frac{1}{\rho_{\mathrm{s}}}\left(D_{\mathrm{do}}+D_{\mathrm{fo}}\right)\right\rangle \\
& -\frac{1}{l}\left[K_{y} h_{\mathrm{o}}^{1.5} c_{\mathrm{o}}\right]_{y=l}
\end{aligned}
$$

Mathematically, $\frac{1}{l} \int_{0}^{l} h_{\mathrm{o}} c_{\mathrm{o}} d y=\left\langle h_{\mathrm{o}} c_{\mathrm{o}}\right\rangle$, The term $\left\langle h_{\mathrm{o}} c_{\mathrm{o}}\right\rangle$, when expanded as a Taylor series around local-scaleaveraged sheet flow depth $\left\langle h_{\mathrm{o}}\right\rangle$ and local-scale-averaged sediment concentration $\left\langle c_{\mathrm{o}}\right\rangle$ reduces to the zeroth order: $\left\langle h_{\mathrm{o}} c_{\mathrm{o}}\right\rangle=\left\langle h_{\mathrm{o}}\right\rangle\left\langle c_{\mathrm{o}}\right\rangle$. The zeroth order approximation is commonly employed in the literature (Kavvas and Govindaraju, 1992; Tayfur and Kavvas, 1994; Chen et al., 1994; Horne and Kavvas, 1997; Kavvas et al., 1998; Tayfur and Kavvas, 1998). When the covariance function has not been estimated from the field observations, then the best one can do is to reduce the second order equation to the zeroth order (Kavvas et al., 1998). This study, however, uses a different notation in local-scale averaging as $\left\langle h_{\mathrm{o}}\right\rangle\left\langle c_{\mathrm{o}}\right\rangle=\bar{h}_{\mathrm{o}} \bar{c}_{\mathrm{o}}$. In other words, for any state variably $\Psi_{\mathrm{o}}$, the local-scale-averaged state variable is defined as $\bar{\Psi}_{\mathrm{o}}=\frac{1}{l} \int_{0}^{l} \Psi_{\mathrm{o}} d y$. Thus,

$$
\begin{gathered}
\frac{\partial\left\langle\bar{h}_{\mathrm{o}} \bar{c}_{\mathrm{o}}\right\rangle}{\partial t}+\frac{\partial}{\partial x}\left(K_{x}^{\prime} \bar{h}_{\mathrm{o}} 1.5 \bar{c}_{\mathrm{o}}\right) \\
=\frac{1}{\rho_{\mathrm{s}}}\left(\bar{D}_{\mathrm{do}} \bar{D}_{\mathrm{fo}}\right)-\frac{K_{y l}}{l} h_{\mathrm{ol}}^{1.5} c_{\mathrm{ol}}
\end{gathered}
$$

where $\bar{c}_{\mathrm{o}}=$ the local-scale averaged sediment concentration $\left(L^{3} / L^{3}\right)$ on interrill-area; $h_{\mathrm{ol}}=$ the flow depth at the outlet section of interrill-area, right adjacent to the rill section $(L)$; $c_{\mathrm{ol}}=$ the sediment concentration at the outlet section of interrill-area, right adjacent to the rill section $\left(L^{3} / L^{3}\right)$;
$\bar{D}_{\mathrm{do}}=$ the local-scale averaged soil detachment rate due to raindrops on interrill-area $\left(M / L^{2} / T\right)$; and $\bar{D}_{\mathrm{fo}}=$ the localscale averaged soil detachment/deposition rate by sheet flow on interrill-area $\left(M / L^{2} / T\right)$.

There are 4 unknown variables in Eq. (16) $-\bar{h}_{\mathrm{o}}, \bar{c}_{\mathrm{o}}, h_{\mathrm{ol}}$, and $c_{\mathrm{ol}}$. On the other hand, there are 2 equations - one for $\overline{\mathrm{h}}_{\mathrm{o}}$ (Eq. (4)) and one for $\overline{\mathrm{c}}_{\mathrm{o}}$ (Eq. (16)). Therefore, in order to close the system, there is a need to develop a relation between the variables at the outlet section $\left(h_{\mathrm{ol}}\right.$, and $\left.c_{\mathrm{ol}}\right)$ and the corresponding local-scale averaged variables $\left(\bar{h}_{\mathrm{o}}\right.$ and $\left.\bar{c}_{\mathrm{o}}\right)$.

In order to relate flow depth at the outlet section of an interrill area width to the local-scale averaged flow depth on that section, Tayfur and Kavvas (1994) assumed, based upon the earlier results of Govindaraju et al. (1988), a sine flow profile [i.e. $\left.h_{\mathrm{o}}(x, y, t)=h_{\mathrm{ol}}(x, t) \sin \left(\frac{\pi y}{2 l}\right)\right]$ for flow over an interrill-area which resulted in the flow depth at the outlet section $\left(h_{\mathrm{ol}}\right)$ to be 1.57 times the local-scale averaged flow depth on that section $\left(\bar{h}_{\mathrm{o}}\right)$; i.e., $h_{\mathrm{ol}}=1.57 \bar{h}_{\mathrm{o}}\left(\right.$ or $\left.h_{\mathrm{ol}}=\frac{\pi}{2} \bar{h}_{\mathrm{o}}\right)$.

In order to relate the sediment concentration at the outlet section to the mean sediment concentration along the interrill-area width in the flow direction, the point SST equation based on the diffusion wave approximation was solved over a hypothetical plot having a smooth bare surface. Several simulation runs over the surface under different average gradients ( $2 \%$ to $20 \%$ ) were performed. The ratio of the sediment concentration at the outlet section of the plot to the mean sediment concentration along the plot length in the flow direction was computed for each simulation run. The ratio changed between almost 1 and 2, with higher ratios for very mild slopes and lower ratios for very steep slopes. On the average, however, the ratio was 1.5 . Hence, the sediment concentration at the outlet section of an interrill-area right adjacent to the rill section $\left(c_{\mathrm{ol}}\right)$ (Fig. 2) was assumed to be equal to 1.5 times the local-scale-averaged sediment concentration on that section $\left(\bar{c}_{\mathrm{ol}}\right)$; i.e., $c_{\mathrm{ol}}=1.5 \bar{c}_{\mathrm{o}}$

Thus, the local-scale-averaged interrill-area SST equation is obtained as:

$$
\begin{aligned}
& \frac{\partial\left(\bar{h}_{\mathrm{o}} \bar{c}_{\mathrm{o}}\right)}{\partial t}+\frac{\partial}{\partial x}\left(K_{x}^{\prime} \bar{h}_{\mathrm{o}}^{1.5} \bar{c}_{\mathrm{o}}\right) \\
& \quad=\frac{1}{\rho_{\mathrm{s}}}\left(\bar{D}_{\mathrm{do}}+\bar{D}_{\mathrm{fo}}\right)-2.95 \frac{K_{y l}}{l} \bar{h}_{\mathrm{o}}{ }^{1.5} \bar{c}_{\mathrm{o}}
\end{aligned}
$$

Eq. (17) is the local-scale-averaged version of the pointscale interrill-area SST Eq. (10). The last term on the right hand side of Eq. (17) represents the sink term that is the sediment load going from an interrill-area to the adjacent rill section.

Eq. (17) is quasi-two dimensional. It is in $1 \mathrm{D}$, yet it contains the 2D properties of the sheet SST. In the numerical solution of this equation, one requires the average values of the model parameters over the local-scale interrill-area (Fig. 3) at each point along the $x$-direction (along the hillslope length). Such a solution is not attractive from the data collection and computation point of view. Therefore, in order to avoid such a problem and to obtain an areally averaged conservation equation that is still local-scale but 
covers the length of a hillslope in the $x$-direction toward the stream, one has to average Eq. (17) along the hillslope length $\left(L_{x}\right)$ (Fig. 3). The local-scale areal averaging is performed as:

$$
\begin{aligned}
& \frac{1}{L_{x}} \int_{0}^{L_{x}} \frac{\partial\left(\bar{h}_{\mathrm{o}} \bar{c}_{\mathrm{o}}\right)}{\partial t} d x+\frac{1}{L_{x}} \int_{0}^{L_{x}} \frac{\partial}{\partial x}\left(K_{x}^{\prime} \bar{h}_{\mathrm{o}}^{1.5} \bar{c}_{\mathrm{o}}\right) d x \\
& \quad=\frac{1}{L_{x}} \int_{0}^{L_{x}} \frac{1}{\rho_{\mathrm{s}}}\left(\bar{D}_{\mathrm{do}}+\bar{D}_{\mathrm{fo}}\right) d x-\frac{2.95}{L_{x}} \int_{0}^{L_{x}} \frac{K_{y l}}{l} \bar{h}_{\mathrm{o}}^{1.5} \bar{c}_{\mathrm{o}} d x
\end{aligned}
$$

Integration of Eq. (18) yields:

$$
\begin{gathered}
\frac{\partial\left\langle\bar{h}_{\mathrm{o}} \bar{c}_{\mathrm{o}}\right\rangle}{\partial t}+\frac{1}{L_{x}}\left[K_{x}^{\prime} \bar{h}_{\mathrm{o}}^{1.5} \bar{c}_{\mathrm{o}}\right]_{x=L_{x}}-\frac{1}{L_{x}}\left[K_{x}^{\prime} \bar{h}_{\mathrm{o}}^{1.5} \bar{c}_{\mathrm{o}}\right]_{x=0} \\
=\left\langle\frac{1}{\rho_{\mathrm{s}}}\left(\bar{D}_{\mathrm{do}}+\bar{D}_{\mathrm{fo}}\right)\right\rangle-2.95\left\langle\frac{K_{y l}}{l} \bar{h}_{\mathrm{o}}{ }^{1.5} \bar{c}_{\mathrm{o}}\right\rangle
\end{gathered}
$$

where \langle\rangle denotes the local-scale areal averaging operator.

Mathematically, $\frac{1}{L_{x}} \int_{0}^{L_{x}} \bar{h}_{\mathrm{o}} \bar{c}_{\mathrm{o}} d x=\left\langle\bar{h}_{\mathrm{o}} \bar{c}_{\mathrm{o}}\right\rangle$, The term $\left\langle\overline{\mathrm{h}}_{\mathrm{o}} \overline{\mathrm{c}}_{\mathrm{o}}\right\rangle$, when expanded as a Taylor series around localscale areally averaged sheet flow depth $\left\langle\overline{\mathrm{h}}_{\mathrm{o}}\right\rangle$ and local-scale areally averaged sediment concentration $\left\langle\overline{\mathrm{c}}_{\mathrm{o}}\right\rangle$, reduces to the zeroth order: $\left\langle\overline{\mathrm{h}}_{\mathrm{o}} \overline{\mathrm{c}}_{\mathrm{o}}\right\rangle=\left\langle\overline{\mathrm{h}}_{\mathrm{o}}\right\rangle\left\langle\overline{\mathrm{c}}_{\mathrm{o}}\right\rangle$. This study, however, employed a different notation in local-scale areal averaging as $\left\langle\overline{\mathrm{h}}_{\mathrm{o}} \overline{\mathrm{c}}_{\mathrm{o}}\right\rangle=h_{\mathrm{o}}^{\prime} \mathrm{c}_{\mathrm{o}}^{\prime}$. In other words, for any local-scale averaged state variable $\psi^{-}{ }_{0}$, the local-scale areally averaged state variable is expressed as $\Psi_{\mathrm{o}}^{\prime}=\frac{1}{L_{x}} \int_{0}^{L_{x}} \bar{\Psi}_{\mathrm{o}} d x$. It is assumed that at the upstream end of the interrill-area $(x=0)$ (Fig. 3) the sediment concentration is zero. In numerical solutions of the point SST equation, the zero sediment concentration is often employed as the upstream boundary condition (Govindaraju and Kavvas, 1991; Kavvas and Govindaraju, 1992; Tayfur, 2001, 2002; and Tayfur and Singh, 2004). Hence, the third term on the left hand side of Eq. (19) becomes zero. Thus,

$$
\begin{aligned}
& \frac{\partial\left(h_{\mathrm{o}}^{\prime} c_{\mathrm{o}}^{\prime}\right)}{\partial t}+\frac{1}{L_{x}}\left(K_{x L_{x}}^{\prime} h_{\mathrm{o} L_{x}} \bar{c}_{\mathrm{o} L_{x}}\right) \\
& =\frac{1}{\rho_{\mathrm{s}}}\left(D_{\mathrm{do}}^{\prime}+D_{\mathrm{fo}}^{\prime}\right)-2.95 K_{y l}^{\prime} h_{\mathrm{o}}^{\prime 1.5} c_{\mathrm{o}}^{\prime}
\end{aligned}
$$

where $c_{\mathrm{o}}^{\prime}=$ the local-scale areally averaged interrill-area sediment concentration $\left(L^{3} / L^{3}\right) ; \bar{h}_{\mathrm{o} L_{x}}=$ the local-scale averaged flow depth at the hillslope bottom $(L) ; \bar{c}_{\mathrm{o} L_{x}}=$ local-scale averaged sediment concentration at the hillslope bottom $\left(L^{3} / L^{3}\right)$; $D_{\mathrm{do}}^{\prime}=$ the local-scale areally averaged soil detachment rate due to raindrops over an interrill-area $\left(M / L^{2} / T\right)$; and $D_{\mathrm{fo}}^{\prime}=$ the local-scale areally averaged soil detachment/deposition rate by sheet flow over an interrill-area $\left(M / L^{2} / T\right)$.

There are 4 unknown variables in Eq. (20) - $h_{\mathrm{o}}^{\prime}, c_{\mathrm{o}}^{\prime}, \bar{h}_{\mathrm{o} L_{x}}$, $\bar{c}_{\mathrm{o} L_{x}}$. On the other hand there are 2 equations - one for $h_{\mathrm{o}}^{\prime}$ (Eq. (5)) and one for $c_{\mathrm{o}}^{\prime}$ (Eq. (20)). Therefore, there is a need to close the system by developing relations between the variables at the hillslope bottom $\left(\bar{h}_{o L_{x}}\right.$ and $\left.\bar{c}_{o L_{x}}\right)$ and the corresponding localscale areally averaged variables $\left(h_{\mathrm{o}}^{\prime}\right.$ and $\left.c_{\mathrm{o}}^{\prime}\right)$.

Tayfur and Kavvas (1998) assumed a sine flow profile over an interrill-area [i.e., $\bar{h}_{\mathrm{o}}(x, t)=h_{o L_{x}}(t)=\sin \left(\frac{\pi x}{2 L_{x}}\right)$ ] which resulted in the flow depth at the bottom of the section $\left(\bar{h}_{\mathrm{o} L_{x}}\right)$ to be 1.57 times the local-scale-averaged flow depth on that section $\left(h_{\mathrm{o}}^{\prime}\right)$; i.e., $\bar{h}_{\mathrm{o} L_{x}}=1.57 h_{\mathrm{o}}^{\prime}\left(\right.$ or $\left.\bar{h}_{o L_{x}}=\frac{\pi}{2} h_{\mathrm{o}}^{\prime}\right)$.

In order to relate the sediment concentration at the bottom of the interrill-area to the average sediment concentration on that section, several simulation runs by the numerical solution of the point SST model over an interrill-area having a smooth surface, under different gradients of $2 \%$ to $20 \%$, were performed. The runs resulted in the sediment concentration at the bottom of the interrill-area to be, on average, 1.5 times the mean sediment concentration along the interrill-area length in the flow direction. Hence, the local-scale averaged sediment concentration at the downstream end of the interrill-area $\left(x=L_{x}\right)$ (Fig. 3) $\left(\overline{\mathrm{c}}_{o L_{x}}\right)$ is assumed to be equal to 1.5 times the local-scale areally averaged sediment concentration over that interrill-area $\left(c_{\mathrm{o}}^{\prime}\right)$; i.e., $\overline{\mathrm{c}}_{o L_{x}}=1.5 c_{\mathrm{o}}^{\prime}$.

Thus, the local-scale areally averaged interrill-area SST equation is obtained as:

$$
\frac{\partial\left(h_{\mathrm{o}}^{\prime} c_{\mathrm{o}}^{\prime}\right)}{\partial t}+\frac{2.95}{L_{x}}\left(K_{x_{L x}}^{\prime} h_{\mathrm{o}}^{\prime 1.5} c_{\mathrm{o}}^{\prime}\right)=\frac{1}{\rho_{\mathrm{s}}}\left(D_{\mathrm{do}}^{\prime}+D_{\mathrm{fo}}^{\prime}\right)-2.95 K_{y l}^{\prime} h_{\mathrm{o}}^{\prime 1.5} c_{\mathrm{o}}^{\prime}
$$

Eq. (21) is the local-scale areally averaged version of the local-scale-averaged interrill-area SST Eq. (17) and the point-scale interrill-area SST Eq. (10). It requires only the average values of the model parameters over the whole individual interrill-area.

\subsubsection{Rill sediment transport}

The cross-sectionally (local-scale) averaged sediment transport in 1D in a rill section can be expressed as:

$$
\frac{\partial\left(h_{\mathrm{r}} c_{\mathrm{r}}\right)}{\partial t}+\frac{\partial}{\partial x}\left[K_{\mathrm{r}} R^{0.5} h_{\mathrm{r}} c_{\mathrm{r}}\right]=\frac{1}{\rho_{\mathrm{s}}} D_{\mathrm{fr}}+\left(2.95 \bar{h}_{\mathrm{o}}^{1.5} \bar{c}_{\mathrm{o}}\right)\left(\frac{K_{y l_{i}}}{w_{\mathrm{r}}}\right)
$$

where

$D_{\mathrm{fr}}=\varphi\left\lfloor\eta\left(\tau_{\mathrm{r}}-\tau_{\mathrm{c}}\right)^{k}-\rho_{\mathrm{s}} c_{\mathrm{r}} K_{\mathrm{r}} R^{0.5} h_{\mathrm{r}}\right\rfloor$

where $c_{\mathrm{r}}=$ the cross-sectionally averaged sediment concentration in rill section $\left(L^{3} / L^{3}\right) ; D_{\mathrm{fr}}=$ the cross-sectionally averaged soil detachment/deposition rate by rill flow $(M /$ $\left.L^{2} / T\right)$; and $\tau_{\mathrm{r}}=\gamma R S_{\mathrm{r}}$, the cross-sectionally averaged rill shear stress $\left(M / L^{2}\right)$.

In Eq. (22), the soil detachment due to raindrops in a rill section is neglected. According to Foster (1982), the raindrop impact is a dominant factor in the detachment of soil particles on interrill-areas whereas in rills detachment and transport by flow are the dominant factors. The last term on the right hand side of Eq. (22) represents the local-scale lateral sediment fluxes coming into the rill from the adjacent interrill-areas $[i=1,2$; two adjacent interrill-areas, as shown in Fig. 2]. In the numerical solution of Eq. (22), one requires the crosssectionally averaged (local-scale averaged) (Fig. 3) values of the model parameters at each point along the $x$-direction (along the hillslope length). Such a solution is not attractive from the data collection and computation point of view. 
Therefore, in order to avoid such a problem and to obtain areally averaged conservation equation that is still local-scale but covers the length of a hillslope in the $x$-direction toward the stream, one has to average Eq. (22) along the hillslope length $\left(L_{x}\right)$ (local-scale areal averaging) (Fig. 3).

\subsubsection{Local-scale areally averaged rill sediment transport}

The cross-sectionally (local-scale) averaged sediment transport Eq. (22) is averaged along the rill length $\left(L_{x}\right)$, i.e., it is integrated along $L_{x}$ (Fig. 3) and then the resulting integrals are divided by $L_{x}$, resulting in:

$$
\begin{gathered}
\frac{\partial\left\langle h_{\mathrm{r}} c_{\mathrm{r}}\right\rangle}{\partial t}+\frac{1}{L_{x}}\left[K_{\mathrm{r}} R^{0.5} h_{\mathrm{r}} c_{\mathrm{r}}\right]_{x=L_{x}}-\frac{1}{L_{x}}\left[K_{\mathrm{r}} R^{0.5} h_{\mathrm{r}} c_{\mathrm{r}}\right]_{x=0} \\
=\left\langle\frac{1}{\rho_{\mathrm{s}}} D_{\mathrm{fr}}\right\rangle+2.95\left\langle\bar{h}_{\mathrm{o}}^{1.5-} c_{\mathrm{o}} \frac{K_{y l_{i}}}{w_{\mathrm{r}}}\right\rangle
\end{gathered}
$$

Mathematically, $\frac{1}{L_{\mathrm{r}}} \int_{0}^{L_{x}} h_{\mathrm{r}} c_{\mathrm{r}} d x=\left\langle h_{\mathrm{r}} c_{\mathrm{r}}\right\rangle$ where \langle\rangle denotes the local-scale areal averaging operator. The term $\left\langle h_{\mathrm{r}} c_{\mathrm{r}}\right\rangle$, when expanded as a Taylor series around local-scale areally averaged rill flow depth $\left\langle h_{\mathrm{r}}\right\rangle$ and local-scale areally averaged rill sediment concentration $\left\langle c_{\mathrm{r}}\right\rangle$, reduces to the zeroth order: $\left\langle h_{\mathrm{r}} c_{\mathrm{r}}\right\rangle=\left\langle h_{\mathrm{r}}\right\rangle\left\langle c_{\mathrm{r}}\right\rangle$. This study, however, used a different notation in local-scale areal averaging of rill sediment transport as $\left\langle h_{\mathrm{r}}\right\rangle\left\langle c_{\mathrm{r}}\right\rangle=h_{\mathrm{r}}^{\prime} c_{\mathrm{r}}^{\prime}$. In other words, for any local-scale state variable $\psi_{\mathrm{r}}^{-}$, the local-scale areal averaged state variable can be expressed as $\Psi_{\mathrm{r}}^{\prime}=\frac{1}{L_{\mathrm{r}}} \int_{0}^{L_{x}} \bar{\Psi}_{\mathrm{r}} d x$. The sediment concentration at the upstream end of the rill (Fig. 3) is assumed to be equal to zero resulting in the third term on the right hand side of Eq. (24) to become zero. Tayfur and Kavvas (1998) made a similar assumption for the flow depth at the upstream end of the rill. Thus,

$$
\frac{\partial h_{\mathrm{r}}^{\prime} c_{\mathrm{r}}^{\prime}}{\partial t}+\frac{1}{L_{x}}\left(K_{r L_{x}} R_{L_{x}}^{0.5} h_{r L_{x}} c_{r L_{x}}\right)=\frac{1}{\rho_{\mathrm{s}}} D_{\mathrm{fr}}^{\prime}+2.95\left(h_{\mathrm{o}}^{\prime 1.5} c_{\mathrm{o}}^{\prime} K_{Y_{i}}^{\prime}\right)
$$

where $c_{\mathrm{r}}^{\prime}=$ the local-scale areally averaged sediment concentration in the rill section $\left(L^{3} / L^{3}\right) ; h_{\mathrm{r} L_{x}}=$ the local-scale averaged flow depth at the downstream end of the rill $(L)$; $c_{\mathrm{r} L_{x}}=$ the local-scale averaged sediment concentration at the downstream end of the rill $\left(L^{3} / L^{3}\right) ; D_{\mathrm{fr}}^{\prime}=$ the local-scale areally averaged soil detachment/deposition rate by rill flow $\left(M / L^{2} / T\right)$; and $R_{L x}=$ the hydraulic radius of the rill section (assumed to be rectangular) at the downstream end of the rill. The last term on the right hand side of Eq. (25) represents the areal lateral sediment load coming into the rill from the adjacent interrill-areas $[i=1,2$; two adjacent interrill-areas as shown in Fig. 2].

There are 4 unknown variables in Eq. (25) $-h_{\mathrm{r}}^{\prime}, c_{\mathrm{r}}^{\prime}, h_{\mathrm{r} L_{\mathrm{r}}}$ and $c_{\mathrm{r} L_{x}}$. On the other hand, there are 2 equations - one for $h_{\mathrm{r}}^{\prime}(\mathrm{Eq}$. (7)) and one for $c_{\mathrm{r}}^{\prime}$ (Eq. (25)). Therefore, in order to close the system, there is a need to develop relations between the localscale averaged variables at the downstream end of the rill section $\left(h_{\mathrm{r} L_{x}}\right.$ and $\left.c_{\mathrm{r} L_{x}}\right)$ and the corresponding local-scale areally averaged variables on the same section $\left(h_{\mathrm{r}}^{\prime}\right.$ and $\left.c_{\mathrm{r}}^{\prime}\right)$.
In order to relate the local-scale averaged flow depth at the downstream end of the rill to local-scale areally averaged rill flow depth, Tayfur and Kavvas (1998) assumed a sine flow profile in a rill section [i.e. $\left.h_{\mathrm{r}}(x, t)=h_{r_{L_{x}}}(t) \sin \left(\frac{\pi x}{2 L_{x}}\right)\right]$ which resulted in the cross-sectionally-averaged flow depth at the downstream end of the rill $\left(h_{\mathrm{r} L_{x}}\right)$ to be equal to 1.57 times the local-scale areally averaged flow depth in that rill section $\left(h_{\mathrm{r}}^{\prime}\right)$, i.e., $h_{\mathrm{r} L_{x}}=1.57 h_{\mathrm{r}}^{\prime}\left(\right.$ or $h_{r_{L_{x}}}=\frac{\pi}{2} h_{\mathrm{r}}^{\prime}$ ). In this study, it is also assumed in a rill section that the local-scale-averaged sediment concentration at the downstream end of the rill (Fig. 3) $\left(c_{\mathrm{r} L_{\mathrm{r}}}\right)$ is equal to 1.5 times the local-scale areally averaged sediment concentration in that rill section $\left(c_{\mathrm{r}}^{\prime}\right)$; i.e., $c_{\mathrm{r} L_{x}}=1.5 c_{\mathrm{r}}^{\prime}$.

The second term on the left hand side of Eq. (25) requires the evaluation of hydraulic radius at the downstream end of the rill $\left(R_{L x}\right)$. This, in turn, requires the evaluation of rill flow depth at the downstream end of the rill. The flow depth at the downstream end of the rill is, as pointed out above, related to the areally averaged rill flow depth as $h_{r L_{x}}=\frac{\pi}{2} h_{\mathrm{r}}^{\prime}\left(\right.$ or $h_{\mathrm{rL} L_{x}}=1.57 h_{\mathrm{r}}^{\prime}$ ). Therefore, $R_{L x}=\frac{\left(w_{r_{L x}}\right)\left(\frac{\pi}{2} h_{\mathrm{r}}^{\prime}\right)}{\left(w_{r_{L I}}+\pi h^{\prime}\right)}$.

Thus, the local-scale areally averaged rill sediment transport equation is obtained

$\frac{\partial\left(h_{\mathrm{r}}^{\prime} c_{\mathrm{r}}^{\prime}\right)}{\partial t}+\left[\frac{2.95 K_{R} h_{\mathrm{r}}^{\prime \prime 15} c_{\mathrm{r}}^{\prime}}{\left(w_{r_{L x}}+\pi h_{\mathrm{r}}^{\prime}\right)^{0.5}}\right]=\frac{1}{\rho_{\mathrm{s}}} D_{\mathrm{fr}}^{\prime}+2.95 h_{\mathrm{o}}^{\prime 1.5} c_{\mathrm{o}}^{\prime} K_{Y_{i}}^{\prime}$

where $K_{R}=K_{r_{L x}} w_{r_{L x}}^{0.5} / L_{x}$.

Eq. (26) is a local-scale areally averaged version of the local-scale (cross-sectionally) averaged rill sediment transport Eq. (22) and requires only the average values of physical model parameters of the whole rill.

\subsection{Large-scale (hillslope-scale) areal averaging}

\subsubsection{Large-scale areal averaging of interrill-area SST equation}

The developed local-scale areally averaged Eq. (21) is for modelling SST over an individual interrill-area. However, there may be many individual interrill-areas over a whole hillslope. Therefore, it is not desirable to solve SST for each interrill-area. This is not an efficient way from a computational and fieldwork perspective. Therefore, it is desirable to average the local-scale areally averaged SST Eq. (21) over the whole hillslope. The hillslope-scale averaging is accomplished by the statistical averaging of Eq. (21) over the whole hillslope (Fig. 3):

$$
\begin{aligned}
& \frac{\partial\left\langle h_{\mathrm{o}}^{\prime} c_{\mathrm{o}}^{\prime}\right\rangle}{\partial t}+2.95\left\langle K_{X}^{\prime} h_{\mathrm{o}}^{\prime 1.5} c_{\mathrm{o}}^{\prime}\right\rangle \\
& \quad=\frac{1}{\rho_{\mathrm{s}}}\left(\left\langle D_{\mathrm{do}}^{\prime}\right\rangle+\left\langle D_{\mathrm{fo}}^{\prime}\right\rangle\right)-2.95\left\langle K_{y l}^{\prime} h_{\mathrm{o}}^{\prime 1.5} c_{\mathrm{o}}^{\prime}\right\rangle
\end{aligned}
$$

where \langle\rangle stands for the statistical average (expectation) value of a variable over the whole hillslope; and $K_{X}^{\prime}=K_{x_{L^{\prime}} / L x}$.

To obtain an explicit expression from Eq. (27) in terms of statistical averages of its individual terms, it is necessary to find 
the expectations of the product terms containing more than one variable in Eq. (27). These expectations may be found using the Taylor series. The Taylor series expansion of a function $f(x$, $\overline{\mathrm{r}}$ ) around $\overline{\mathrm{r}}=\bar{r}^{\prime}$ can be expressed to the second order as:

$$
\begin{aligned}
f(x, \bar{r})= & f\left(x, \bar{r}^{\prime}\right)+\left.\sum_{i=1}^{n}\left(r_{i}-r_{i}^{\prime}\right) \frac{\partial f(x, \bar{r})}{\partial r_{i}}\right|_{\bar{r}=\bar{r}^{\prime}} \\
& +\left.\frac{1}{2} \sum_{i=1}^{n} \sum_{j=1}^{n} \frac{\partial^{2} f(x, \bar{r})}{\partial r_{i} \partial r_{j}}\right|_{\bar{r}=\bar{r}},\left(r_{i}-r_{i}^{\prime}\right)\left(r_{j}-r_{j}^{\prime}\right)
\end{aligned}
$$

In Eq. (28), $x$ represents the state variable; $\overline{\mathrm{r}}$ represents a set of random parameters, such as slope, roughness coefficient and interrill-area width, and is a random vector; and $\bar{r}^{\prime}$ is the mean value of this random vector. It is assumed that all the randomness in the state variable $x$ is due to the randomness in the parameters of the process. Such an assumption is plausible, since the dynamics is controlled by model parameters. Therefore, any randomness that may occur in the state variable would be due to the randomness that occurs in model parameters. Under this assumption,

$$
\begin{aligned}
\langle f(x, \bar{r})\rangle= & f\left(x, \bar{r}^{\prime}\right) \\
& +\frac{1}{2} \sum_{i=1}^{n} \sum_{j=1}^{n} \frac{\partial^{2} f\left(x, \bar{r}^{\prime}\right)}{\partial r_{i}^{\prime} \partial_{j}^{\prime}} \operatorname{Cov}\left(r_{i}, r_{j}\right)
\end{aligned}
$$

Applying Eq. (29) to Eq. (27),

$$
\begin{aligned}
\left\langle K_{X}^{\prime} h_{\mathrm{o}}^{\prime 1.5} c_{\mathrm{o}}^{\prime}\right\rangle= & K_{X}^{\prime}\left(\bar{r}^{\prime}\right) h_{\mathrm{o}}^{\prime 1.5}\left(\bar{r}^{\prime}\right) c_{\mathrm{o}}^{\prime}\left(\bar{r}^{\prime}\right) \\
& +\frac{1}{2} \sum_{i=1}^{n} \sum_{j=1}^{n} \frac{\partial^{2}\left[K_{X}^{\prime}\left(\bar{r}^{\prime}\right) h_{\mathrm{o}}^{\prime 1.5}\left(\bar{r}^{\prime}\right) c_{\mathrm{o}}^{\prime}\left(\bar{r}^{\prime}\right)\right]}{\partial r_{i}^{\prime} \partial r_{j}^{\prime}} \operatorname{Cov}\left(r_{i}, r_{j}\right)
\end{aligned}
$$

where the vector random variable $\overline{\mathrm{r}}=\left(C_{\mathrm{z}}, S_{\mathrm{o} x}, S_{\mathrm{oy}}, L_{x}\right)$ and $\overline{\mathrm{r}}^{\prime}$ is its hillslope-scale mean vector.

Also in Eq. (27),

$$
\begin{aligned}
\left\langle K_{y l}^{\prime} h_{\mathrm{o}}^{\prime 1.5} c_{\mathrm{o}}^{\prime}\right\rangle= & K_{y l}^{\prime}\left(\bar{r}^{\prime}\right) h_{\mathrm{o}}^{\prime 1.5}\left(\bar{r}^{\prime}\right) c_{\mathrm{o}}^{\prime}\left(\bar{r}^{\prime}\right) \\
& +\frac{1}{2} \sum_{i=1}^{n} \sum_{j=1}^{n} \frac{\partial^{2}\left[K_{y l}^{\prime}\left(\bar{r}^{\prime}\right) h_{\mathrm{o}}^{\prime 1.5}\left(\bar{r}^{\prime}\right) c_{\mathrm{o}}^{\prime}\left(\bar{r}^{\prime}\right)\right]}{\partial r_{i}^{\prime} \partial r_{j}^{\prime}} \operatorname{Cov}\left(r_{i}, r_{j}\right)
\end{aligned}
$$

where the vector random variable $\overline{\mathrm{r}}=\left(C_{\mathrm{z}}, S_{\mathrm{ox}}, S_{\mathrm{oy}}, l\right)$ and $\overline{\mathrm{r}}^{\prime}$ is its hillslope-scale mean vector.

When Eqs. (31) and (30) are substituted back into Eq. (27) and rearranged, the following large-scale (hillslope-scale) areal averaged interrill-area SST equation is obtained:

$$
\begin{aligned}
& \frac{\partial\left(h_{\mathrm{o}}^{\prime}\left(\bar{r}^{\prime}\right) c_{\mathrm{o}}^{\prime}\left(\bar{r}^{\prime}\right)\right)}{\partial t}+1.48 \sum_{i=1}^{n} \sum_{j=1}^{n} \operatorname{Cov}\left(r_{i}, r_{j}\right) \\
& \times\left\{\frac{\partial^{2}\left[K_{X}^{\prime}\left(\bar{r}^{\prime}\right) h_{\mathrm{o}}^{\prime 1.5}\left(\bar{r}^{\prime}\right) c_{\mathrm{o}}^{\prime}\left(\bar{r}^{\prime}\right)\right]}{\partial r_{i}^{\prime} \partial r_{j}^{\prime}}+\frac{\partial\left[K_{y l}^{\prime}\left(\bar{r}^{\prime}\right) h_{\mathrm{o}}^{\prime 1.5}\left(\bar{r}^{\prime}\right) c_{\mathrm{o}}^{\prime}\left(\bar{r}^{\prime}\right)\right]}{\partial r_{i}^{\prime} \partial r_{j}^{\prime}}\right\} \\
& +2.95\left\{K_{X}^{\prime}\left(\bar{r}^{\prime}\right) h_{\mathrm{o}}^{\prime 1.5}\left(\bar{r}^{\prime}\right) c_{\mathrm{o}}^{\prime}\left(\bar{r}^{\prime}\right)+K_{y l}^{\prime}\left(\bar{r}^{\prime}\right) h_{\mathrm{o}}^{\prime 1.5}\left(\bar{r}^{\prime}\right) c_{\mathrm{o}}^{\prime}\left(\bar{r}^{\prime}\right)\right\} \\
& \quad=\frac{1}{\rho_{\mathrm{s}}}\left[D_{\mathrm{do}}^{\prime}\left(\bar{r}^{\prime}\right)+D_{\mathrm{fo}}^{\prime}\left(\bar{r}^{\prime}\right)\right]
\end{aligned}
$$

where $\bar{r}$ is the vector random variable and $\bar{r}^{\prime}$ is its hillslopescale mean vector; $h_{\mathrm{o}}^{\prime}\left(\bar{r}^{\prime}\right)=$ the hillslope-scale-averaged interrill-area sheet flow depth computed by Eq. (8); $c_{\mathrm{o}}^{\prime}\left(\bar{r}^{\prime}\right)=$ the hillslope-scale-averaged interrill-area sediment concentration; $D_{\mathrm{do}}^{\prime}\left(\bar{r}^{\prime}\right)=$ the hillslope-scale-averaged soil detachment rate by raindrops over an interrill-area; and $D_{\text {fo }}^{\prime}\left(\overline{\mathrm{r}}^{\prime}\right)=$ the hillslope-scale-averaged soil detachment/deposition rate by sheet flow over an interrill-area.

\subsubsection{Large-scale areal averaging of rill sediment transport equation}

The developed local-scale areally averaged rill sediment transport Eq. (26) is for modelling sediment transport for a whole individual rill section located on a hillslope. However, the hillslope may contain a large number of rills and it is not desirable to solve sediment transport in each rill from a computational and fieldwork perspective. Hence, it is necessary to average Eq. (26) over the whole hillslope section. The hillslope-scale averaging is accomplished by the statistical averaging of Eq. (26) over the whole hillslope (Fig. 3). The expectation of the product terms containing more than one variable is found using the Taylor series expansion. Only the first two moments of the series are considered and it is further assumed that all the randomness in the state variable is due to the randomness in the parameters of the processes. The hillslope-scale averaging is accomplished in a similar fashion as it is done and presented above for the interrill-area SST equation. Hence, for the sake of brevity, the final version of the derived hillslope-scale averaged rill sediment transport equation is:

$$
\begin{aligned}
& \frac{\partial\left(h_{\mathrm{r}}^{\prime}\left(\bar{r}^{\prime}\right) c_{\mathrm{r}}^{\prime}\left(\bar{r}^{\prime}\right)\right)}{\partial t}+1.48 \sum_{i=1}^{n} \sum_{j=1}^{n} \operatorname{Cov}\left(r_{i}, r_{j}\right) \\
& \quad \times\left\{\frac{\partial^{2}\left[\frac{K_{R}\left(\bar{r}^{\prime}\right) h_{\mathrm{r}}^{\prime .5}\left(\bar{r}^{\prime}\right) c_{\mathrm{r}}^{\prime}\left(\bar{r}^{\prime}\right)}{\left.\left(w_{r_{L_{x}}+\pi h_{r}^{\prime}}\left(\bar{r}^{\prime}\right)\right)^{.05}\right]}\right.}{\partial r_{i}^{\prime} \partial r_{j}^{\prime}}-\frac{\partial^{2}\left[K_{Y_{1}}^{\prime}\left(\bar{r}^{\prime}\right) h_{\mathrm{o}}^{\prime 1.5}\left(\bar{r}^{\prime}\right) c_{\mathrm{r}}^{\prime}\left(\bar{r}^{\prime}\right)\right]}{\partial r_{i}^{\prime} \partial r_{j}^{\prime}}\right. \\
& \left.-\frac{\partial^{2}\left[K_{Y_{2}}^{\prime}\left(\bar{r}^{\prime}\right) h_{\mathrm{o}}^{\prime 1.5}\left(\bar{r}^{\prime}\right) c_{\mathrm{r}}^{\prime}\left(\bar{r}^{\prime}\right)\right]}{\partial r_{i}^{\prime} \partial r_{j}^{\prime}}\right\}+2.95\left\{\frac{K_{R}\left(\bar{r}^{\prime}\right) h_{\mathrm{r}}^{\prime 1.5}\left(\bar{r}^{\prime}\right) c_{\mathrm{r}}^{\prime}\left(\bar{r}^{\prime}\right)}{\left(w_{r_{L x}+\pi n h_{\mathrm{r}}^{\prime}}\left(\bar{r}^{\prime}\right)\right)^{0.5}}\right. \\
& \left.-h_{\mathrm{o}}^{\prime 1.5}\left(\bar{r}^{\prime}\right) c_{\mathrm{r}}^{\prime}\left(\bar{r}^{\prime}\right)\left[K_{Y_{1}}^{\prime}\left(\bar{r}^{\prime}\right)+K_{Y_{2}}^{\prime}\left(\bar{r}^{\prime}\right)\right]\right\}=\frac{1}{\rho_{\mathrm{s}}} D_{\mathrm{fr}}^{\prime}\left(\bar{r}^{\prime}\right)
\end{aligned}
$$

where $\bar{r}$ is the vector random variable and $\bar{r}^{\prime}$ is its hillslopescale mean vector; $h_{\mathrm{r}}^{\prime}\left(\bar{r}^{\prime}\right)=$ the hillslope-scale-averaged rill flow depth computed by Eq. (9); $c_{\mathrm{r}}^{\prime}\left(\bar{r}^{\prime}\right)=$ the hillslope-scaleaveraged rill sediment concentration; and $D_{\mathrm{fr}}^{\prime}\left(\bar{r}^{\prime}\right)=$ the hillslope-scale-averaged rill soil detachment/deposition rate.

\subsection{The use of areally averaged model}

Govindaraju et al. (1992) and Govindaraju and Kavvas (1992) quantified the rill structure through spatial scales. Fig. 4 shows the variation of an average property of the hillslope with increasing distance along the cross-slope spatial coordinate (indicated as $y$-direction in Fig. 1). Over very small averaging intervals, the average property fluctuates 


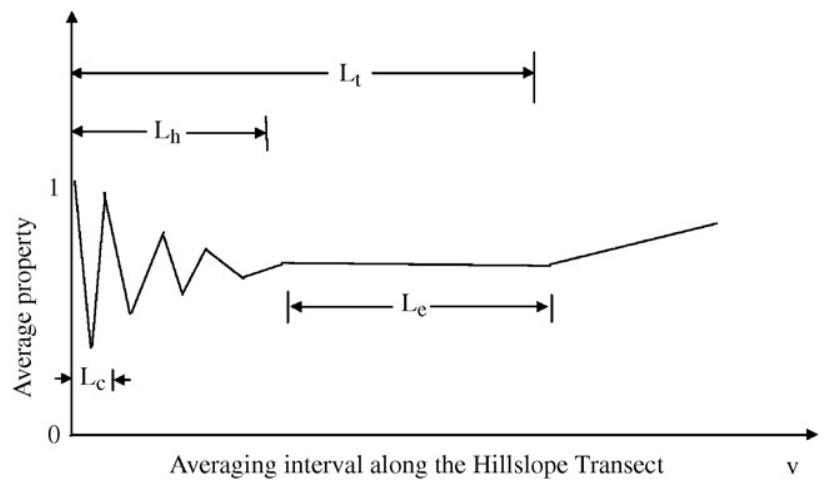

Fig. 4. Variation of an averaged property with increasing distance and identification of spatial scales $\left(L_{\mathrm{c}}\right.$ : characteristic length scale; $L_{\mathrm{h}}$ : ergodic length scale; $L_{\mathrm{t}}$ : terrain length scale; and $L_{\mathrm{e}}$ : region of ergodicity).

very rapidly due to the highly irregular microtopography. This length scale is a measure of the rapidity of the fluctuations in the rilled soil surface and it is called as characteristic length scale $\left(L_{\mathrm{c}}\right)$. As the averaging interval increases, the hillslope average property attains a stable value. The scale at which this occurs is called the local spatial stationary length scale $\left(L_{\mathrm{h}}\right)$. This stable value may change at very large values of the averaging interval due to changes in terrain which induce large-scale spatial nonstationarity. This length scale is called the terrain length scale $\left(L_{\mathrm{t}}\right)$ which is likely to be larger than the width of an individual straight single hillslope. $L_{\mathrm{t}}$ is more important for analysis at watershed scale. The region where local spatial stationarity is applicable (indicated by the region $\left[L_{\mathrm{h}}, L_{\mathrm{t}}\right]$ ) is called the region of ergodicity. Ergodicity represents the equivalence of spatial averages taken over the realization of a spatial hillslope property to the ensemble averages of this property. Over the range of this length scale $\left(L_{\mathrm{e}}\right)$, spatial averages may be used to represent the ensemble averages. The size of the averaging width at which ergodicity applies is of the utmost importance for the continuum representation and this scale is essential for analysis at hillslope-scale (Govindaraju and Kavvas, 1992).

Govindaraju et al. (1992) and Govindaraju and Kavvas (1992), employing a rill indicator function as

$I(x, t, y)=\left\{\begin{array}{ccc}1 & \text { if }(y, y+\Delta y) \quad \text { contains a rill } \\ 0 & \text { otherwise }\end{array}\right.$

defined the expected spatial rill density (ESRD) as

$\lambda(x, t, y)=\frac{1}{y} \int_{0}^{y} I(x, t, y) d y$

Eq. (35) shows that the ESRD $\lambda(x, t, y)$ is an average property over the distance $y$. It represents the proportion of transect that is occupied by the rills. Therefore, ESRD may be interpreted as the average rill occurrence probability over the particular transect as a function of the hillslope averaging interval. Using ESRD as the average property of interest and Eq. (34), they showed that ergodic length scale is about $6-8 \mathrm{~m}$
(20-25 ft). Therefore, the developed areally averaged model can be applied to a hillslope whose width may be larger than $6 \mathrm{~m}$ and smaller than the terrain length scale that could be as wide as $1000 \mathrm{~m}$ in nature.

To obtain the complete solution for sediment transport at the scale of a hillslope, the hillslope-scale averaged interrillarea sheet flow Eq. (8) and hillslope-scale averaged rill flow Eq. (9) are first solved simultaneously to obtain the hillslopescale averaged flow depths and fluxes over interrill-areas and in rill sections that are the required inputs in the solution of the hillslope-scale sediment transport Eqs. (32) and (33). Then, hillslope-scale sediment transport Eqs. (32) and (33) are solved simultaneously for each time step. Eq. (32) is first solved to calculate the hillslope-scale averaged sediment discharge going to the neighbouring rill section and coming to the stream located at the downstream end of the interrill-area section. Then, Eq. (33) is solved to calculate the hillslope-scale averaged sediment discharge coming from the rill section to the stream located at the end of the hillslope bottom. In order to determine the total sediment discharge from a hillslope to a neighbouring stream, the number of rills over a hillslope is estimated first. GIS uses the digital elevation model that can provide information on elevation, slope, and aspect of the catchment. By using 10-m DEM, one can delineate the rill structure of a hillslope and estimate the probability of the rill occurrence $\lambda$ as described above [and given in more details in Govindaraju et al., 1992], Govindaraju and Kavvas (1992) and Kavvas and Govindaraju (1992). By weighted averaging, the hillslope-scale averaged rill sediment discharge to the stream is multiplied by $\lambda$, and the hillslope-scale averaged interrill-area sediment discharge to the stream is multiplied by $(1-\lambda)$ in order to weigh the relative contributions of rill sediment load and interrill-area sediment load to loads to the neighbouring stream at the scale of a hillslope. These products are then summed up to find the total sediment discharge from a hillslope to the neighbouring stream adjacent to the particular hillslope.

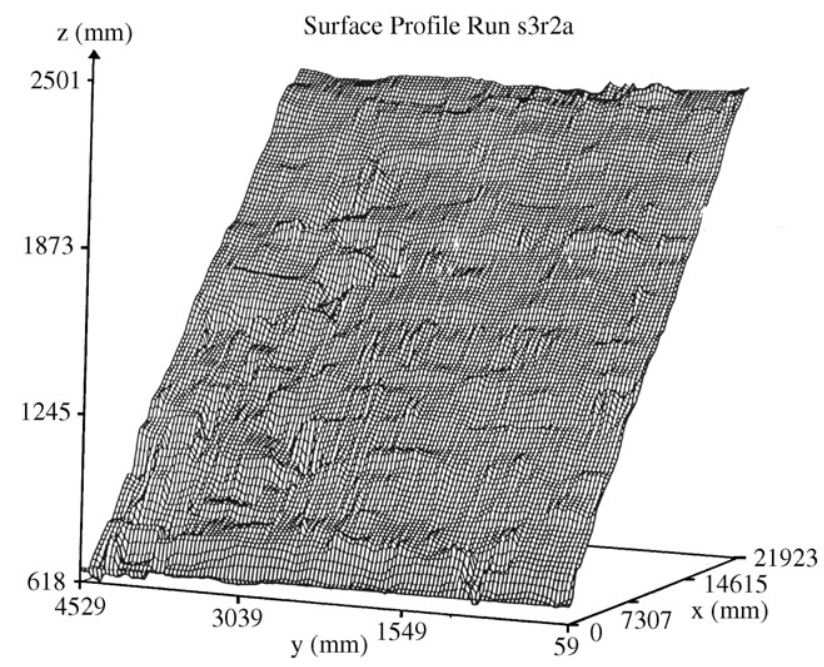

Fig. 5. Microtopography surface profile of plot S3R2A (Barfield et al., 1983). 


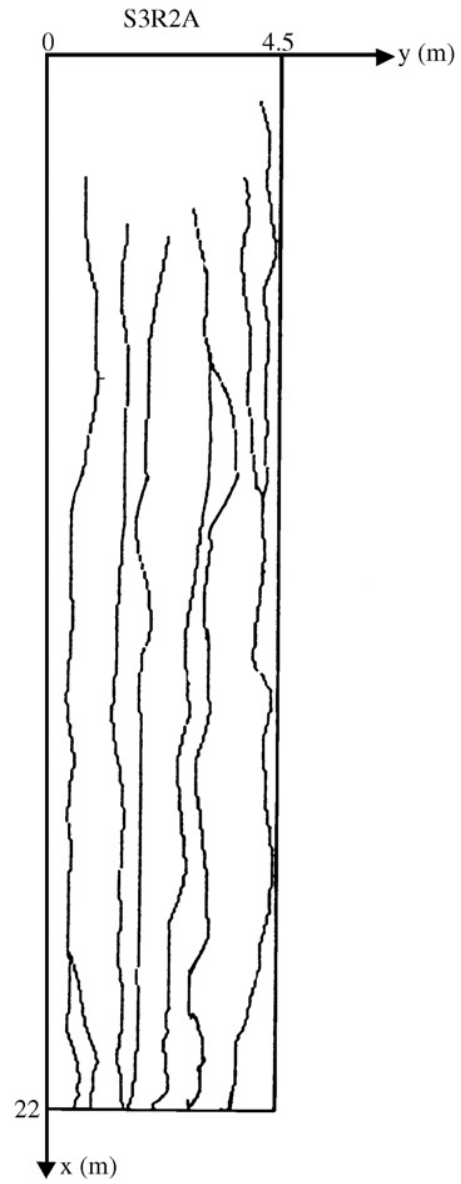

Fig. 6. Rill distribution over plot S3R2A (Barfield et al., 1983).

Note that the newly developed model does not impose any limit on the interrill area size nor on the rill distribution. By GIS using $10 \mathrm{~m}$ DEM, one can obtain information on the distribution of rills and interrill areas to acquire the input for the model. However the model requires that the width of a hillslope be greater than the ergodic length scale but smaller than the terrain length scale. The information on hydrological variables such as rainfall and infiltration can be obtained by the measurements. The newly developed areal averaged model, on the other hand, assumes that the rill structure essentially unchanged during the course of a single rainfallrunoff-erosion-sediment transport event. Thus the ESRD and mean rill width have no temporal dependence and are functions of space only. This assumption is, in essence valid for moderate rainstorms whose intensity is not strong enough to change the rill structure significantly.

\section{Large-scale areally averaged model testing}

\subsection{Model testing against point-scale model}

The developed large-scale (hillslope-scale) areally averaged SST model was tested against the point-scale model of Tayfur and Singh (2004) that employed a point-scale representation to quantitatively investigate the effects of replacing spatially varying microtopographic surface, roughness, and infiltration rate with their corresponding average values on the sediment transport dynamics. Note that Tayfur (2002) has already successfully tested the point-scale sediment transport model against the measured sediment discharge data sets obtained from Kilic and Richardson (1973) and Tayfur and Kavvas (1998) have successfully tested the flow part of the areally averaged model against the flow discharge data obtained from Barfield and Storm (1989, personal communications).

Data from an experimental plot, labelled as S3R2A, (Barfield et al., 1983; Barfield and Storm, 1989 personal communication) was used. The three-dimensional picture of the plot is given in Fig. 5. The plot is $22 \mathrm{~m}$ long and $4.5 \mathrm{~m}$ wide. The rill distribution belonging to plot S3R2A is given in Fig. 6 (Barfield et al., 1983; Barfield and Storm, 1989, personal communication). Tayfur and Singh (2004) employed the point-scale representation to model twodimensional SST over the rough surface of plot S3R2A. They used information on the microtopography of the plot at a grid size of $60 \mathrm{~cm}$. For application of the large-scale (hillslope-scale) areally averaged model, the statistical averages of main ( $x$-direction in Fig. 1) and transverse $(y$ direction in Fig. 1) slopes were found from microtopographic data. Also, the statistical estimate of the rill occurrence probability was obtained from the rill distribution. The statistical averages of mean interrill-area and rill widths were also obtained.

The estimated statistical averages of main and transverse slopes, interrill-area and rill widths, and rill occurrence probability are given in Table 1 . The average rill slope was assumed to be equal to the average mean slope of interrillarea $\left(S_{\mathrm{r}}=S_{\mathrm{ox}}\right)$. The computed variance and related covariance values of model parameters are summarised in Table 1. This

Table 1

Statistical information on Model Parameter of Plot S3R2A

\begin{tabular}{|c|c|c|c|c|c|c|}
\hline Average main slope & Average & lope & Averag & terrill-area width (m) & Average rill width (m) & Rill occurrence probability density \\
\hline$S_{\mathrm{o} x}$ & $S_{\mathrm{oy}}$ & & $(l)$ & & $\left(w_{\mathrm{r}}\right)$ & $\lambda$ \\
\hline 0.0816 & 0.0366 & & 0.305 & & 0.102 & 0.134 \\
\hline $\operatorname{Var}\left(S_{\mathrm{o} x}\right)$ & $\operatorname{Var}\left(S_{\mathrm{o} y}\right)$ & $\operatorname{Var}(l)$ & & $\operatorname{Cov}\left(S_{\mathrm{o} x}, S_{\mathrm{o} y}\right)$ & $\operatorname{Cov}\left(S_{\mathrm{o} x}, l\right)$ & $\operatorname{Cov}\left(S_{\mathrm{r}}, w_{\mathrm{r}}\right)$ \\
\hline $1.38 \mathrm{E}-05$ & 0.00186 & 0.126 & & 0.022 & $2.78 \mathrm{E}-04$ & $3.95 \mathrm{E}-03$ \\
\hline
\end{tabular}




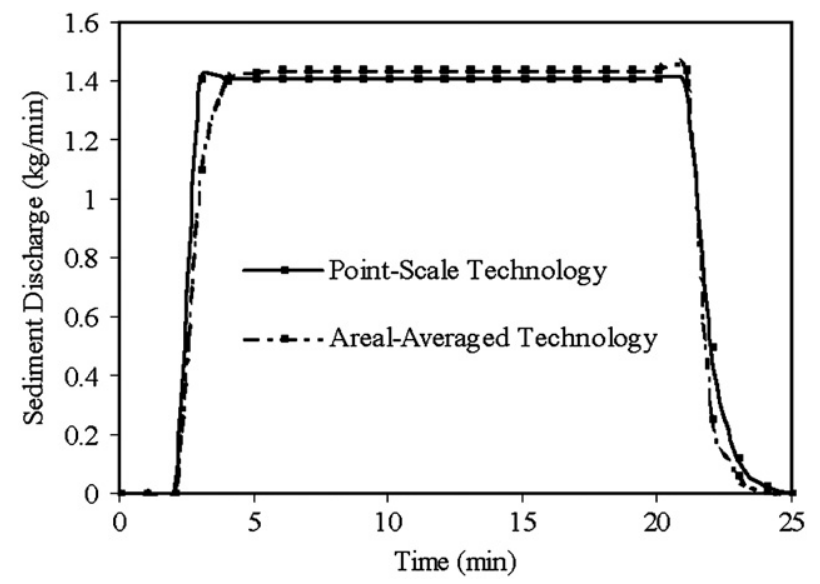

Fig. 7. Areally averaged model versus point-scale model.

study employed $C_{\mathrm{z}}=14.4 \mathrm{~m}^{0.5} / \mathrm{s}, n=0.42, \alpha=0.0022 \mathrm{~kg} / \mathrm{m}^{2} /$ $\mathrm{mm}, \eta=0.12, \varphi=24 \mathrm{~m}^{-1}, d=0.001 \mathrm{~m}, \rho_{\mathrm{s}}=1500 \mathrm{~kg} / \mathrm{m}^{3}$, $\beta=1.8$ and $k=1.5$. These values are within the ranges suggested in the literature (Kilinc and Richardson, 1973; Woolhiser, 1974; Foster, 1982; and Sharma et al., 1993). It was assumed that the plot is subjected to $117 \mathrm{~mm} / \mathrm{h}$ rainfall intensity for duration of $20 \mathrm{~min} .7 \mathrm{~mm} / \mathrm{h}$ constant infiltration rate was assumed.

Fig. 7 compares the sedimentographs obtained by the solution of the point-scale equations (Tayfur and Singh, 2004) and newly developed the hillslope-scale-averaged equations of the present study. The performance of hillslopescale-averaged equations is comparable to that of the pointscale equations. This implies that the developed model can be employed to model SST at a hillslope-scale. Fig. 8 shows the ratio of the sediment loads from interrill-areas and rill sections for the case in Fig. 7. It is seen that although the rill occurrence probability is $13.4 \%$, about $96 \%$ of the load come from rill sections. This result is consistent with the observation of Govindaraju et al. (1992) who carried out rainfall-runoff-sediment transport experiments over a steep cut experimental hillslope of high rill density. They observed that most of the sediment loads came from rill sections.

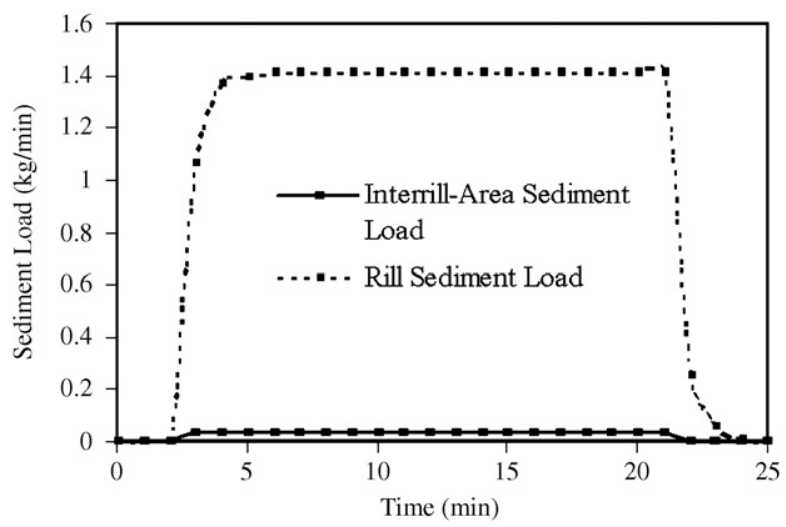

Fig. 8. Comparison of sediment loads in interrill-area rill sections (rill occurrence probability is $14 \%$ ).
Table 2

Summary of rill structure information measured at backhorn summit experimental hillslope (Govindaraju et al., 1992) ESRD: Expected spatial rill density

\begin{tabular}{|c|c|c|c|}
\hline Distance & ESRD & Mean rill depth & Mean rill width \\
\hline (m) & $(\%)$ & $(\mathrm{cm})$ & $(\mathrm{cm})$ \\
\hline 9 & $14 \%$ & 7 & 10 \\
\hline 10.5 & $17.5 \%$ & 8 & 14 \\
\hline 12 & $15 \%$ & 9 & 16 \\
\hline 13.5 & 25 & 9.5 & 19 \\
\hline 15 & 28 & 11 & 22 \\
\hline 16.5 & $34 \%$ & 11.5 & 22.5 \\
\hline 18 & 33 & 12 & 23.5 \\
\hline 19.5 & $36.5 \%$ & 12 & 24 \\
\hline 21 & 38 & 13 & 25 \\
\hline 22.5 & $37 \%$ & 13 & 24.5 \\
\hline 24 & 38 & 13 & 25.5 \\
\hline
\end{tabular}

\subsection{Model testing against experimental data}

The developed model was tested against experimental data obtained from rainfall simulation over a cut bare hillslope located close to Buckhorn Summit in Northern California, USA. The experimental hillslope has a steep slope of about $67 \%$. Experiments were carried out in September 1990. The lower portion of the hillslope, about $15 \mathrm{~m}$ long and $10 \mathrm{~m}$ wide, was subjected to intense rainfall intensity of $152 \mathrm{~mm} / \mathrm{h}$ for duration of $10 \mathrm{~min}$. The sediment laden flow was collected at the downstream along the width of the slope after steady state had been reached. The sediment discharge was measured using a Parshall flume. The rill structure measurements were made using a tape measure and a ruler at 11 locations along the slope spaced at $1.5 \mathrm{~m}$ intervals. Table 2 summarizes the measured rill depth, rill width, and expected spatial rill density. From previous experiments conducted in July 1990 on the same hillslope section, the surface roughness for this hillslope was obtained by Govindaraju et al. (1992) as $C_{\mathrm{z}}=16.6 \mathrm{~m}^{0.5} / \mathrm{s}$ (Chezy roughness coefficient). Laboratory saturated hydraulic conductivity tests on 23 samples collected from this hillsope, on the average, yielded $K_{\mathrm{s}}=37.8 \mathrm{~mm} / \mathrm{h}$. The infiltration rate was modelled by the Horton's formula and the parameters of the model were obtained by Govindaraju et al. (1992) using the

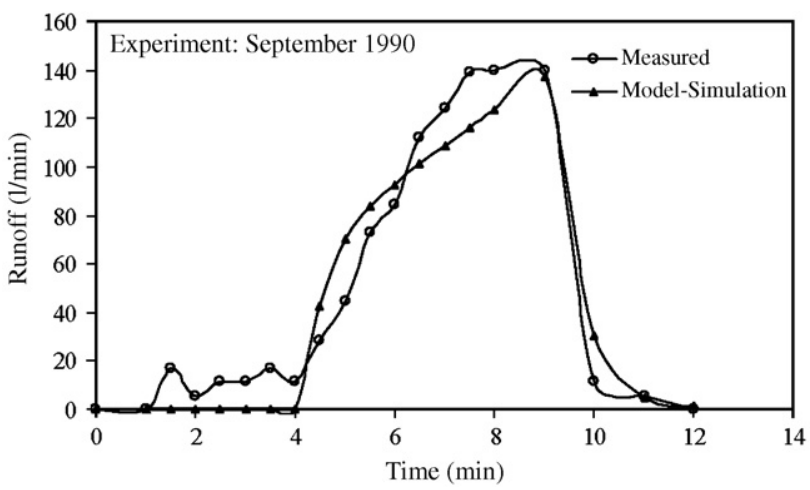

Fig. 9. Simulation of measured runoff from experimental hillslope at Buckhorn summit in Northern California. 


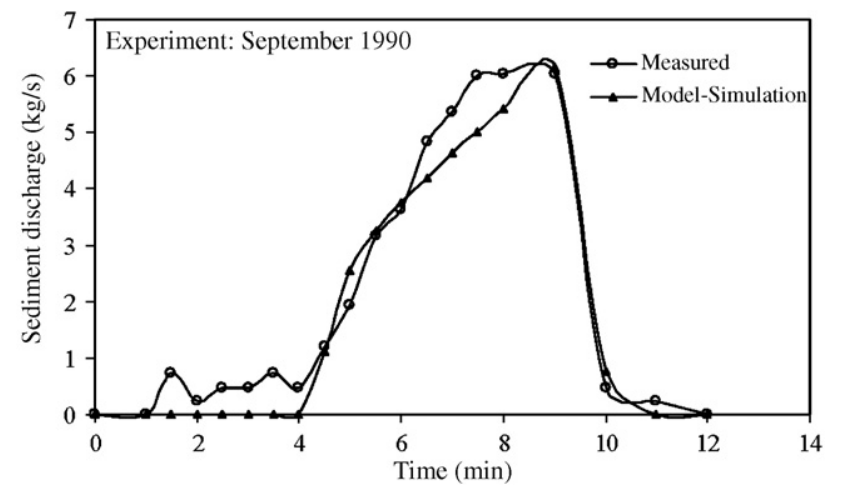

Fig. 10. Simulation of measured sediment loads from experimental hillslope at Buckhorn summit in Northern California.

data from experiments conducted in July 1990 as $k=0.00141$ / $\mathrm{s}$ (rate constant) and $f_{\mathrm{o}}=127 \mathrm{~mm} / \mathrm{h}$ (initial infiltration rate before the rain event starts). The sediment density was measured as $2662 \mathrm{~kg} / \mathrm{m}^{3}$ (Govindaraju et al., 1992). The details of the experiment can be obtained from Govindaraju et al. (1992).

Figs. 9 and 10 show simulation of measured runoff rate and sediment discharge data by the newly developed areal averaged sediment transport equations, respectively. As seen the model satisfactorily predicted both the runoff and sediment rates. The computed mean absolute errors for Figs. 9 and 10 are $11.07 \mathrm{l} / \mathrm{min}$ and $0.382 \mathrm{~kg} / \mathrm{s}$, respectively indicating the capability of the newly developed model in simulating the runoff and erosion and sediment transport processes over an individual bare rilled hillslope.

\section{Summary and concluding remarks}

Modelling of sheet sediment transport induced by the rainfall-runoff process at a hillslope-scale entails the flow dynamics and sediment transport dynamics. The hillslopescale areally averaged sediment transport equations were developed, treating sediment transport in rills as onedimensional and on interrill-areas as two-dimensional and their interaction. The advantage of hillslope-scale areal averaging is that one avoids solving for sediment transport on each interrill-area and in each rill, since there may be many interrill-areas and rills located on the hillslope. In the hillslopescale areal averaging, it is assumed that the randomness in the state variable (e.g., sediment concentration) is due to the randomness in the model parameters (e.g., soil particle diameter, interrill-area width, rill width, and $x$ - and $y$-direction slopes) which, in turn, control the state variable. Such an approach results in simple and easily solvable equations. All the model parameters are assumed to be spatially stationary random functions. The ensemble averages (expectations) of the terms containing more than one variable in the large-scale areally averaged equations are obtained by the method of regular perturbation with only the first two moments being considered.
Although the hillslope-scale areally averaged model uses significantly less information on the land-surface microtopography, it performs as well as does the point-scale model. For example, Tayfur and Singh (2004) used transverse and main slopes at each grid nodal point when they employed the pointscale sediment transport equation for modelling sediment transport over S3R2A experimental plot. They used a grid size of $60 \mathrm{~cm}$ since they had such detailed information on the microtopography of the plot. Meanwhile, the newly developed hillslope-scale averaged model used only the average values of the transverse and main slopes for the whole hillslope section of the experimental plot.

Hillslope-scale areal averaging overcomes the difficulty faced in estimating the sediment transport parameters due to heterogeneous microtopography and surface roughness conditions at the scale of a hillslope. Hillslope-scale areally averaged sediment transport equations also circumvent the difficulty of computing sediment transport at small grid spacing. One requires local roughness and local $x$ - and $y$ direction slope values at every nodal point of a computational network mesh over a hillslope when modelling two-dimensional SST by the point-scale sediment transport equations. This results in a very substantial parameter estimation problem. On the other hand, when one models SST by the newly developed hillslope-scale averaged sediment transport equations derived in the present study, one requires only the averaged values of one roughness coefficient, one $x$-direction slope and one $y$-direction slope over the whole interrill-area, and one $x$-direction bed slope for all rills over the whole hillslope section. In real-world problems, one never has the detailed microtopographic information at each nodal point. However, by means of digital elevation information (digital elevation map) with a standard resolution of about $30 \mathrm{~m}$, one can obtain estimates of hillslope-scale parameters in Eqs. (32) and (33). It is important to note that the hillslope-scale parameters in Eqs. (32) and (33) are the averages and the covariances of the local-scale parameter values and not of the microtopographic parameter values. The parameter values which are obtained over a $30 \mathrm{~m}$ by $30 \mathrm{~m}$ grid are consistent with the scale of the local-scale parameter values. A hillslope has typical dimensions in the range of 100-500 $\mathrm{m}$ in the mass transport direction and in the range of 100-1000 $\mathrm{m}$ in the longitudinal direction (orthogonal to the mass transport direction). If a hydrologist is provided with only $30 \mathrm{~m} \times 30 \mathrm{~m}$ resolution data, he/she would have in the range of 11-550 local-scale sediment transport parameter sample values that could be utilized to estimate the mean $\bar{r}^{\prime}$ and the covariance $\operatorname{Cov}\left(r_{i}, r_{j}\right)$ parameters which appear in Eqs. (32) and (33).

\section{Acknowledgments}

The author is grateful to B.J. Barfield and D.E. Storm of the Department of Agricultural Engineering, College of Agriculture, University of Kentucky, for the field experimental data presented herein. 


\section{Appendix A}

\section{Notation}

$c_{\mathrm{o}} \quad$ The sediment concentration by volume on interrillarea $\left(L^{3} / L^{3}\right)$;

co Local-scale averaged sediment concentration $\left(L^{3} / L^{3}\right)$;

$c_{\mathrm{o}}^{\prime} \quad$ The local-scale areally averaged interrill-area sediment concentration $\left(L^{3} / L^{3}\right)$;

$c_{\mathrm{ol}} \quad$ Sediment concentration at the outlet section $\left(L^{3} / L^{3}\right)$;

$\overline{\mathrm{c}}_{\mathrm{o} L_{x}} \quad$ Local-scale averaged sediment concentration at the hillslope bottom $\left(L^{3} / L^{3}\right)$;

$c_{\mathrm{r}} \quad$ The cross-sectionally average sediment concentration in rill section $\left(L^{3} / L^{3}\right)$;

$c_{\mathrm{r}}^{\prime} \quad$ The local-scale areally averaged sediment concentration in the rill section $\left(L^{3} / L^{3}\right)$;

$c_{\mathrm{r} L_{x}} \quad$ The local-scale averaged sediment concentration at the downstream end of the rill $(L)$;

$C_{\mathrm{z}} \quad$ Chezy's roughness coefficient $\left(L^{1 / 2} / T\right)$;

$d \quad$ The particle diameter $(L)$;

$D_{\text {do }} \quad$ The soil detachment rate by raindrops over interrillarea $\left(M / L^{2} / T\right)$;

$\bar{D}_{d o} \quad$ The local-scale-averaged soil detachment rate due to raindrops on an interrill-area $\left(M / L^{2} / T\right)$;

$D_{\text {do }}^{\prime} \quad$ The local-scale areally averaged soil detachment rate due to raindrops over an interrill-area $\left(M / L^{2} / T\right)$;

$D_{\text {fo }} \quad$ The soil detachment/deposition rate by sheet flow over an interrill-area $\left(M / L^{2} / T\right)$;

$\bar{D}_{\text {fo }} \quad$ The local-scale-averaged soil detachment/deposition rate by sheet flow on an interrill-area $\left(M / L^{2} / T\right)$;

$D_{\text {fo }}^{\prime} \quad$ The local-scale areally averaged soil detachment/ deposition rate by sheet flow over an interrill-area $\left(M / L^{2} / T\right)$;

$D_{\text {fr }} \quad$ The cross-sectionally averaged soil detachment/ deposition rate by rill flow $\left(M / L^{2} / T\right)$;

$D_{\text {fr }}^{\prime} \quad$ The local-scale areally averaged soil detachment rate by rill flow $\left(M / L^{2} / T\right)$;

$h_{\mathrm{o}} \quad$ The sheet flow depth $(L)$;

$\bar{h}_{\mathrm{o}} \quad$ The local-scale averaged interrill-area sheet flow depth $(L)$;

$\mathrm{h}_{\mathrm{o}}^{\prime}\left(\overline{\mathrm{r}}^{\prime}\right) \quad$ The large-scale areally averaged interrill-area sheet flow depth $(L)$;

$h_{\mathrm{ol}} \quad$ Flow depth at the outlet section $(L)$;

$\overline{\mathrm{h}}_{o \mathrm{~L} x} \quad$ The local-scale averaged flow depth at the hillslope bottom $(L)$;

$h_{\mathrm{r}} \quad$ The cross-sectionally averaged rill flow depth $(L)$;

$\mathrm{h}_{r}^{\prime}\left(\overline{\mathrm{r}}^{\prime}\right) \quad$ The large-scale areally averaged rill flow depth $(L)$;

$h_{\mathrm{r} L_{x}} \quad$ The local-scale averaged flow depth at the downstream end of the rill $(L)$;

$k \quad$ An exponent;

$l_{\mathrm{d}} \quad$ The loose soil depth $(L)$;

$q_{1} \quad$ The net lateral flow (rainfall minus infiltration) $(L / T)$;

$q_{\mathrm{o}} \quad$ The unit flow discharge in the flow direction $\left(L^{2} / T\right)$;

$R \quad$ the hydraulic radius $(L)$;

$R_{L x} \quad$ The hydraulic radius of the rill section at the downstream end of the rill $(L)$;
$S_{\mathrm{oy}}$

$S_{\mathrm{r}}$

$w_{\mathrm{r}}$

$\alpha$

$\beta$

$\delta$

$\varphi$

$\gamma$

$\gamma_{\mathrm{s}}$

$\eta$

$\rho_{\mathrm{S}}$

$\tau_{\mathrm{o}}$

$\tau_{\mathrm{c}}$

\section{References}

Abrahams, A.D., Parsons, A.J., 1990. Determining the mean depth of overland flow in field studies of flow hydraulics. Water Resour. Res. 26, 501-503.

Abrahams, A.D., Parsons, A.J., Luk, S.-H., 1989. Distribution of depth of overland flow on desert hillslopes and its implication for modeling soil erosion. J. Hydrol. 106, 177-184.

Barfield, B.J., Storm, D.E., 1989, personal communications. Department of Agricultural Engineering, College of Agriculture, University of Kentucky. Lexington, KY.

Barfield, B.J., Barnhisel, R.I., Powell, J.L., Hirschi, M.C. and Moore, I.D., 1983. "Erodibilities and eroded size distribution of Western Kentucky mine spoil and reconstructed topsoil." Institute for Mining and Minerals Research Final Report, Univ. of Kentucky, Lexington, KY.

Bulygin, S.Y., Nearing, M.A., Achasov, A.B., 2002. Parameters of interrill erodibility in the WEPP model. Eurasian Soil Sci. 35 (11), 1237-1242.

Chen, Z.-Q., Govindaraju, R.S., Kavvas, M.L., 1994. Spatial averaging of unsaturated flow equations for areally heterogenous fields: development of models. Water Resour. Res. 30 (2), 523-533.

Emmett, W.W., 1978. Overland Flow. In: Kirkby, M.J. (Ed.), Hillslope Hydrology. John Wiley and Sons, New York, N.Y, pp. 145-176.

Foster, G.R., 1982. Modelling the erosion process. In: Haan, C.T., Johnson, H.P., Brakensiek, D.L. (Eds.), Hydrologic modelling of small watersheds'. ASAE, pp. 295-380.

Govindaraju, R.S., Kavvas, M.L., 1991. Modelling the erosion process over steep slopes: approximate analytical solutions. J. Hydrol. 127, 279-305.

Govindaraju, R.S., Kavvas, M.L., 1992. Characterization of the rill geometry over straight hillslopes through spatial scales. J. Hydrol. 130, 339-365.

Govindaraju, R.S., Jones, S.E., Kavvas, M.L., 1988. On the diffusion wave model for overland flow, 1, solution for steep slopes. Water Resour. Res. 24 (5), 734-744.

Govindaraju, R.S., Kavvas, M.L., Tayfur, G. and Krone, R.B., 1992. "Erosion control of decomposed granite at Buckhorn Summit." Final Report. California Department of Transportation.

Hairsane, P.B., Rose, C.W., 1992a. Modelling water erosion due to overland flow using physical principles, 1. Sheet flow. Water Resour. Res. 28 (1), 237-243.

Hairsane, P.B., Rose, C.W., 1992b. Modelling water erosion due to overland flow using physical principles, 2. Rill flow. Water Resour. Res. 28 (1), 244-250.

Hairsane, P.B., Sander, G.C., Rose, C.W., Parlange, J.-Y., Hogarth, W.L., Lisle, I., Rouhipour, H., 1999. Unsteady soil erosion due to rainfall impact: a model of sediment sorting on the hillslope. J. Hydrol. 220, 115-128.

Horne, F.E., Kavvas, M.L., 1997. Physics of the spatially averaged snowmelt process. J. Hydrol. 191, 179-207. 
Kavvas, M.L., Govindaraju, R.S., 1992. Hydrodynamic averaging of overland flow and soil erosion over rilled hillslopes. Erosion, Debris Flows and Environment in Mountain Regions, Proceedings of the Chengdu Symposium. IAHS Publ, p. 209.

Kavvas, M.L., Chen, Z.Q., Tan, L., Soong, S.T., Terakawa, A., Yoshitani, J., Fukami, K., 1998. A regional-scale land surface parameterization based on areally-averaged hydrological conservation equationuations. Hydrol. Sci. J., IAHS 43 (4), 611-631.

Kilinc, M., Richardson, E.V., 1973. "Mechanics of soil erosion from overland flow generated by simulated rainfall." Hydrology Papers, Colorado State University, Fort Collins, Paper 63.

Lisle, I.G., Rose, C.W., Hogarth, W.L., Hairsine, P.B., Sander, G.C., Parlange, J.-Y., 1998. Stochastic sediment transport in soil erosion. J. Hydrol. 204 (1-4), 217-230.

Meyer, L.D., Foster, G.R. and Romkens, M.J.M., 1975. "Source of soil eroded from upland slopes.” Proc. 1972 Sediment Yield Workshop, U.S. Dept. Agric. Sediment Lab., Oxford, Mississippi, ARS-S-40, USDA, 177-189.

Moss, A.J., Walker, P.H., 1978. Particle transport by continental water flows in relation to erosion, deposition, soil and human activities. Sediment. Geol. 20 (2), 81-139.

Parlange, J.-Y., Hogarth, W.L., Rose, C.W., Sander, G.C., Hairsine, P., Lisle, I., 1999. Addendum to unsteady soil erosion model. J. Hydrol. 217 (1-2), $149-156$.
Sander, G.C., Hairsine, P.B., Rose, C.W., Cassidy, D., Parlange, J.-Y., Hogarth, W.L., Lisle, I.G., 1996. Unsteady soil erosion model, analytical solutions and comparison with experimental results. J. Hydrol. 178 (1-4), 351-367.

Sharma, P.P., Gupta, S.C., Foster, G.R., 1993. Predicting soil detachment by raindrops. Soil Sci. Soc. Am. J. 57, 674-680.

Tayfur, G., 2001. Modelling two dimensional erosion process over infiltrating surfaces. J. Hydrol. Eng., ASCE 6 (3), 259-262.

Tayfur, G., 2002. Applicability of sediment transport capacity models for non-steady state erosion from steep slopes. J. Hydrol. Eng., ASCE 7 (3), $252-259$.

Tayfur, G., Kavvas, M.L., 1994. Spatially averaged conservation equations for interacting rill-interrill area overland flows. J. Hydraul. Eng., ASCE 120 (12), 1426-1448.

Tayfur, G., Kavvas, M.L., 1998. Areal averaged overland flow equations at hillslope scale. Hydrol. Sci. J., IAHS 43 (3), 361-378.

Tayfur, G., Singh, V.P., 2004. Numerical model for sediment transport over nonplanar, non-homogeneous surfaces. J. Hydrol. Eng., ASCE 9 (1), 35-41.

Tayfur, G., Kavvas, M.L., Govindaraju, R.S., Storm, D.E., 1993. Applicability of St. Venant equations for two-dimensional overland flows over rough infiltrating surfaces. J. Hydraul. Eng., ASCE 119 (1), 51-63.

Woolhiser, D.A., 1974. Unsteady free-surface flow problems. Proc. Inst. on Unsteady Flow in Open Channels. Colorado State University, Fort Collins, pp. 195-213. 